\title{
Synthesis and antitumour activity of varitriol and its analogues
}

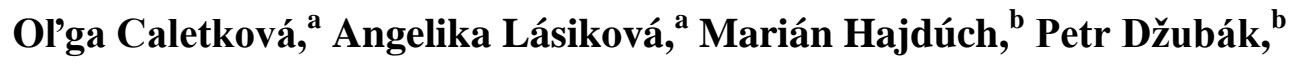 \\ and Tibor Gracza ${ }^{\mathrm{a} *}$ \\ ${ }^{a}$ Department of Organic Chemistry, Slovak University of Technology, Radlinského 9, \\ SK-812 37 Bratislava, Slovakia \\ ${ }^{b}$ Laboratory of Experimental Medicine, Institute of Molecular and Translational Medicine, \\ Faculty of Medicine and Dentistry, Palacký University and University Hospital in Olomouc, \\ Puškinova 6, 77520 Olomouc, Czech Republic \\ E-mail: tibor.gracza@stuba.sk
}

\begin{abstract}
Novel analogues of (+)-varitriol have been synthesised via Julia-Kocienski olefination from $\gamma$-Dribonolactone. Newly prepared compounds were screened for their in vitro cytotoxicity towards certain human tumours and $\mathrm{NCI}_{60}$ cancer cell line panel.
\end{abstract}

Keywords: Cytotoxic natural product, natural product analogues, varitriol, cytotoxic activity, Julia-Kocienski olefination

\section{Introduction}

Marine fungi are an important source of marine natural products. ${ }^{1}$ Recently, the four new compounds, (+)-varitriol 1, varioxirane 2, dihydroterrein 3, and varixanthone 4 have been isolated $^{2}$ from a marine-derived strain of the fungus Emericella variecolor (Figure 1). Amongst them, (+)-varitriol 1 demonstrated a more than 100-fold increased potency over the mean toxicity toward the RXF 393 (renal cancer, $\mathrm{GI}_{50}=1.63 \times 10^{-7} \mathrm{M}$ ), TD-47 (breast cancer, $\mathrm{GI}_{50}=2.10 \times 10^{-}$ ${ }^{7} \mathrm{M}$ ), and SNB (CNS cancer, $\mathrm{GI}_{50}=2.44 \times 10^{-7} \mathrm{M}$ ) cell lines and lower potency against the DU145 (prostate cancer, $\mathrm{GI}_{50}=1.10 \times 10^{-6} \mathrm{M}$ ), HL-60 (TB) (leukaemia, GI $50=2.52 \times 10^{-5} \mathrm{M}$ ), CCRF-CEM (leukaemia, GI ${ }_{50}=2.60 \times 10^{-5} \mathrm{M}$ ), OVCAR-5 (ovarian cancer, $\mathrm{GI}_{50}=6.82 \times 10^{-5}$ $\mathrm{M}$ ), SNB-19 (CNS cancer, $\mathrm{GI}_{50}=9.13 \times 10^{-5} \mathrm{M}$ ), and COLO 205 (colon cancer, $\mathrm{GI}_{50}=9.59 \mathrm{x}$ $10^{-5} \mathrm{M}$ ) cell lines tested within the 60 cell lines panel of the National Cancer Institute (NCI). ${ }^{2,3}$

The combination of potent biological properties and a relatively straightforward molecular structure of (+)-1 generated considerable synthetic interest directed toward the varitriol and its analogues. Since 2006, when Jennings et al. ${ }^{4}$ established the absolute configuration of varitriol by the total synthesis of unnatural enantiomer (-)-1 from D-ribose, thirteen different syntheses of 
(+)- and (-)-varitriol have been reported. ${ }^{4-13}$ In addition, the furanoside and pyranoside analogues of (+)-varitriol have been synthesised, but only a few were evaluated for their antitumour activity. $^{6 \mathrm{~b}, 12 \mathrm{a}, 14}$

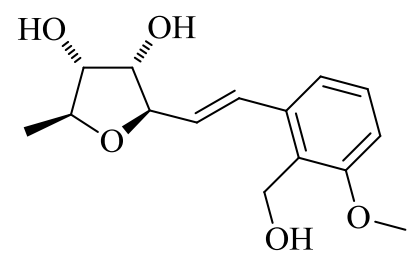

varitriol (+)-1

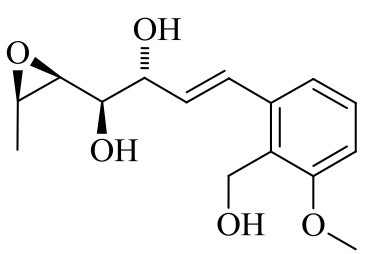

varioxirane 2

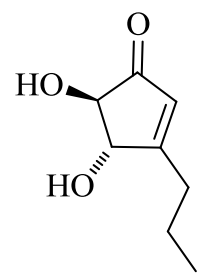

dihydroterrein 3<smiles>C=C(C)[C@H]1COc2c(C)cc3oc4c(C[C@H](OC=O)C(C)(C)O)ccc(O)c4c(=O)c3c2[C@H]1O</smiles>

varixanthone 4

Figure 1. Chemical structures of the metabolites 1-4 from E. variecolor.

As a part of our ongoing project in the synthesis of new polyhydroxylated tetrahydrofurans as potential antitumour agents from monosaccharides, ${ }^{15}$ we have recently developed a short and effective synthesis of varitriol from $\gamma$-D-ribonolactone. ${ }^{7 c}$ Herein, we wish to report the synthesis of varitriol analogues and their antitumour activity.

\section{Results and Discussion}

\section{Chemistry}

The array of interesting biological properties of (+)-1 and the unknown mode of its action motivated us to synthesise a variety of analogues and to examine the bioactivity of structurally diverse ,varitriol-like“ compounds against set of tumour cell lines. New varitriol analogues have been designed by modification of the parent molecule (+)-1 by substitution in aromatic ring $\mathbf{6}$, configuration of furanoside part $\mathbf{5}$ as well as the geometry of the linker 7 (Figure 2).

All target compounds were prepared from $\gamma$-D-ribonolactone using our strategy for synthesis of (+)-varitriol. ${ }^{7 \mathrm{c}}$ The synthesis represents a short and efficient approach to (+)-1 in good overall yield (8 steps, $41 \%$ from D-ribonolactone and dimethylanisole). The key steps of the route include a highly stereoselective introduction of the methyl group at C-1 and Julia-Kocieński olefination with aromatic aldehyde at C-5 of the starting skeleton (Scheme 1). A rapid access to both key fragments, $\mathbf{8}$ and $\mathbf{9}$, as well as the late stage of convergence of the synthesis, make the strategy suitable for the synthesis of the large library of substances for investigation of structureactivity relationship (SAR). 


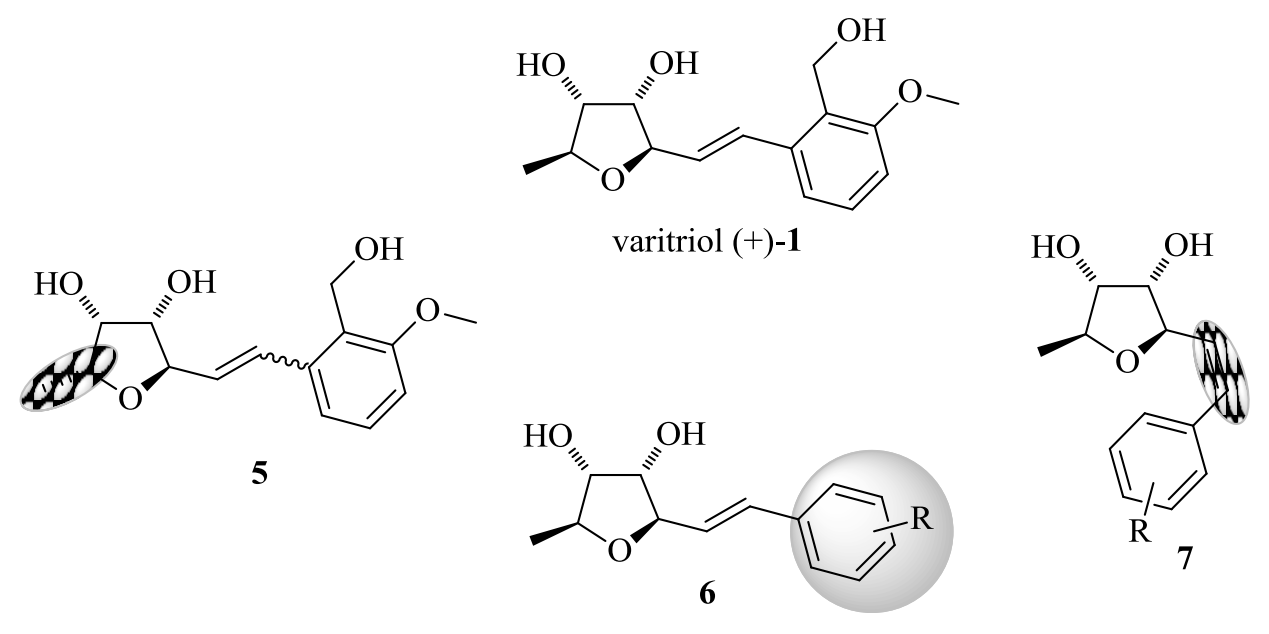

Figure 2. Structure of natural varitriol (+)-1 and its analogues 5, 6, 7.<smiles>COc1cccc(C=CC2OC(C)[C@@H](O)[C@@H]2O)c1CO</smiles><smiles>O=C1O[C@H](CO)[C@@H](O)[C@H]1O</smiles>

g-D-ribonolactone<smiles>C=C</smiles>

Scheme 1. Retrosynthetic analysis of varitriol (+)-1.

The key furanoside fragments for coupling, protected diastereomeric sulfones $\mathbf{8}$ and 19, were prepared from $\gamma$-D-ribonolactone adopting our synthesis ${ }^{7 \mathrm{c}}$ of $(+)-\mathbf{1}$ (Scheme 2). In order to obtain both L-allo and D-talo diastereomers of methylated tetrahydrofuran derivatives $\mathbf{1 3}$ and 14, we changed the reaction sequence of the original synthesis. At first, methyl was introduced at a carbonyl group of the lactone followed by installation of the phenyltetrazole sulfide moiety at C5. In fact, since methylation of the lactone 11 proceeded with high exo-selectivity to produce a sole L-allo configured sulfone 8, silyl protected lactone 12 provided both diastereomers $\mathbf{1 3}, \mathbf{1 4}$ in the same reaction conditions. Thus, following the reaction sequence, primary hydroxyl group of 10 was protected with tert-butyldimethylsilyl chloride followed by partial reduction of the lactone 12 using DIBAL (2 equiv) in THF at $-50{ }^{\circ} \mathrm{C}$, acetylating with acetic anhydride ( 2 equiv) and 4-dimethylaminopyridine (3 equiv) and subsequent treatment of these acetates with trimethylaluminium (3 equiv) in dichloromethane at low temperature. The methylated 
tetrahydrofurans 13 and 14 were prepared in 94\% overall yield. The diastereomers could be readily separated by preparative MPLC to provide $\mathbf{1 3}$ and $\mathbf{1 4}$ in $70 \%$ and $15 \%$ yield, respectively.

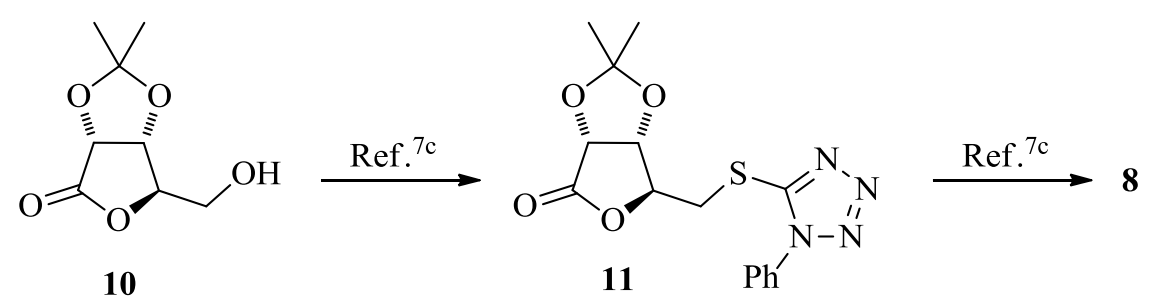

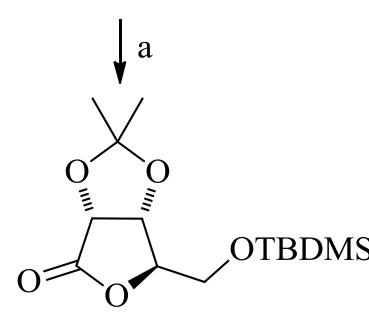

12

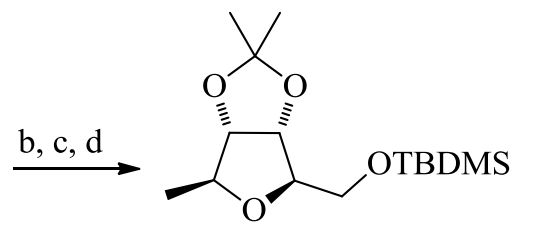

$13(\mathrm{~L}-$ allo $)$

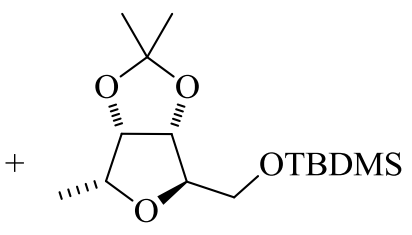

14 (D-talo)<smiles>CC1O[C@H](CS(=O)(=O)c2nnnn2-c2ccccc2)[C@H]2OC(C)(C)O[C@H]12</smiles>

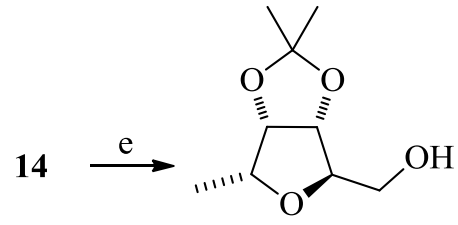

17

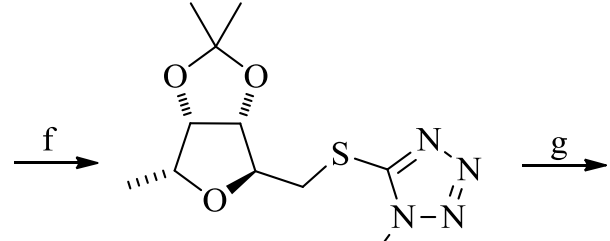

18

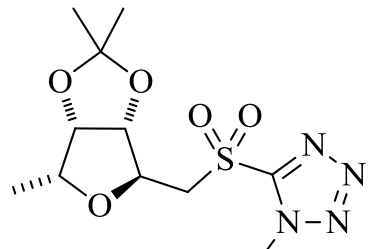

19

Scheme 2. Reagents and conditions: (a) TBDMSCl, Et ${ }_{3} \mathrm{~N}, \mathrm{DMAP}, \mathrm{DMF}, \mathrm{rt}, 8 \mathrm{~h}, 95 \%$; (b) DIBAL, THF, $-50{ }^{\circ} \mathrm{C}, 4 \mathrm{~h}$; (c) $\mathrm{Ac}_{2} \mathrm{O}$, DMAP, $\mathrm{CH}_{2} \mathrm{Cl}_{2}, 0{ }^{\circ} \mathrm{C}$ to rt, $12 \mathrm{~h}$; (d) $\mathrm{Me}_{3} \mathrm{Al}, \mathrm{CH}_{2} \mathrm{Cl}_{2},-30$ to $-18{ }^{\circ} \mathrm{C}, 6 \mathrm{~d}, 94 \%$ from 12 over 3 steps, preparative MPLC, 13 (70\%) and 14 (15\%); (e) TBAF, THF, rt, 12 h, 15 (89\%), 17 (93\%); (f) PTSH, PPh 3 , DIAD, THF, $0{ }^{\circ} \mathrm{C}, 1$ h, 16 (85\%), 18 (94\%); (g) $\mathrm{Mo}(\mathrm{VI}) / \mathrm{H}_{2} \mathrm{O}_{2}, \mathrm{THF}, \mathrm{EtOH}, \mathrm{rt}, 24$ h, 8 (91\%), 19 (91\%).

The second crucial step of both syntheses, which were run in parallel with the pure diastereomers 13 (L-allo) and 14 (D-talo) is installation of the phenyltetrazole sulfide moiety. Firstly, silyl group was removed with tetrabutylammonium fluoride (2 equiv) in THF and alcohols 15 and 17 were exposed to Mitsunobu protocol for displacement of the primary hydroxyl group with phenyltetrazolylthiol. The reaction was carried out under standard reaction 
conditions ${ }^{16,17}$ with PTSH ( 2 equiv), $\mathrm{Ph}_{3} \mathrm{P}$ (1.5 equiv) and DIAD (1.8 equiv) in THF to give the corresponding sulfides $16(85 \%)$ and $18(94 \%)$. The syntheses continued with oxidation of sulfides using hydrogen peroxide/ammonium molybdate in THF and EtOH affording the required sulfones $\mathbf{8}$ and $\mathbf{1 9}$ in good yields (91\%).

Next, the sulfone $\mathbf{8}$ was used in the Kocieński-Julia olefination ${ }^{18}$ with the aldehyde $\mathbf{9 a} \mathbf{a}^{19}$ leading to the protected (+)-1 (6a), and with the set of commercially available aromatic aldehydes 9b-9k (Scheme 3). The couplings were performed under so-called Barbier reaction conditions. ${ }^{20}$ The potassium hexamethyldisilazane (1.8 equiv) was added to the mixture of sulfone 8, and an excess amount of aldehyde 9 (5 equiv) in dimethoxyethane at $-30{ }^{\circ} \mathrm{C}$; the mixture was stirred at room temperature for $10 \mathrm{~h}$. Final removal of the acetonide and acetyl protecting group with $1 \mathrm{M}$ aqueous $\mathrm{HCl}$ in $\mathrm{THF}$ and $\mathrm{NaOMe}$ in $\mathrm{MeOH}$, respectively, furnished target compounds $\mathbf{6 a - k}, \mathbf{7} \mathbf{a}-\mathbf{k}$ as the mixtures of $E / Z$-isomers (Table 1), which were separated by preparative MPLC.

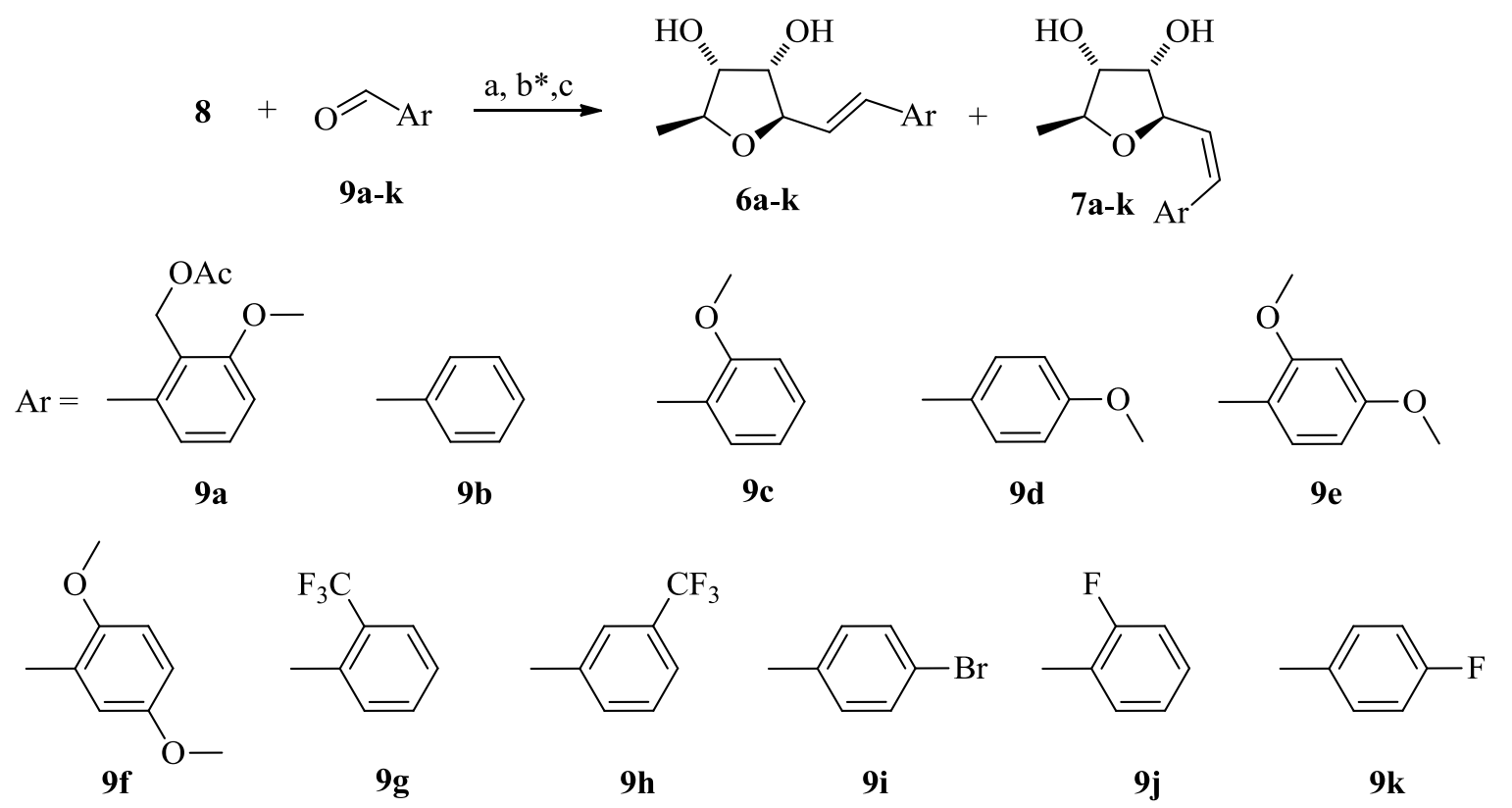

Scheme 3. Reagents and conditions: (a) KHDMS, DME, $-30{ }^{\circ} \mathrm{C}$ to rt, $10 \mathrm{~h}$; (b*) used for 6a, 7a: $\mathrm{NaOMe}, \mathrm{MeOH}, \mathrm{rt}, 4$ h; (c) HCl, THF, rt, 3-12 h; see Table 1.

Table 1. Formation of olefins $6 \mathbf{a}-\mathbf{k}$ and $7 \mathbf{a}-\mathbf{k}$ by reaction of sulfone $\mathbf{8}$ with aldehydes $\mathbf{9 a - k}$

\begin{tabular}{ccccc} 
Entry & Aldehyde & $6 / 7(\% \text { yield })^{\mathrm{a}}$ & $6(\% \text { yield })^{\mathrm{b}}$ & $7(\% \text { yield })^{\mathrm{b}}$ \\
\hline 1 & 9a & 76 & 56 & 14 \\
2 & 9b & 88 & 53 & 26 \\
3 & 9c & 80 & 49 & 3 \\
4 & $9 d$ & 59 & 41 & 18 \\
5 & 9e & 61 & 61 & - \\
\hline
\end{tabular}


Table 1 (continued)

\begin{tabular}{|c|c|c|c|c|}
\hline Entry & Aldehyde & $6 / 7(\% \text { yield })^{\mathrm{a}}$ & $6(\% \text { yield })^{\mathrm{b}}$ & $7(\% \text { yield })^{b}$ \\
\hline 6 & 9f & 59 & 53 & 2 \\
\hline 7 & $9 \mathrm{~g}$ & 41 & 41 & - \\
\hline 8 & $9 \mathrm{~h}$ & 77 & 37 & 25 \\
\hline 9 & $9 \mathrm{i}$ & 98 & 56 & 35 \\
\hline 10 & 9j & 43 & 35 & - \\
\hline 11 & $9 k$ & 42 & 30 & 8 \\
\hline
\end{tabular}

${ }^{\mathrm{a}}$ Combined yield of isolated $\mathbf{6}$ and $7 .{ }^{\mathrm{b}}$ Isolated yield of pure isomers.

In the synthesis of 2-epi-varitriol 5, D-talo configurated sulfone 19 reacted with the corresponding aldehyde 9a under the same reaction conditions as above (Scheme 4). Global deprotection of all hydroxyl groups using the previously described conditions ${ }^{7 \mathrm{c}}$ gave 2-epivaritriol 5 as a mixture of $E / Z$-isomers in the ratio 5:4.

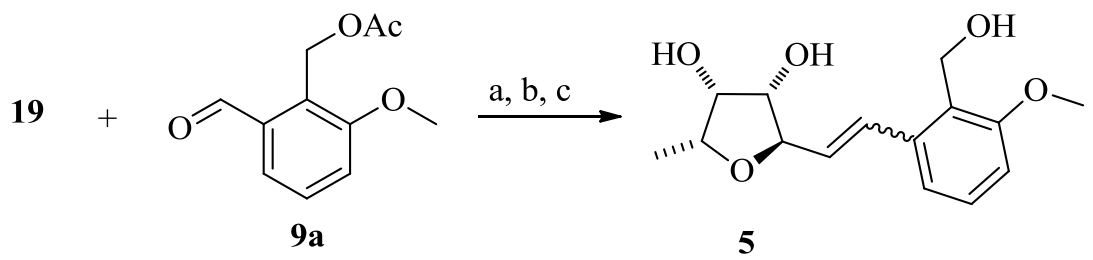

Scheme 4. Reagents and conditions: (a) KHDMS, DME, $-30{ }^{\circ} \mathrm{C}$ to rt, $10 \mathrm{~h}$; (b) $\mathrm{NaOMe}, \mathrm{MeOH}$, rt, $4 \mathrm{~h} ; \mathrm{HCl}$, THF, rt, $5 \mathrm{~h}, 78 \%$ overall yield (E/Z- mixture in the ratio 5:4).

\section{In vitro cytotoxic activity}

Compounds 5, 6 and 7 were evaluated for their in vitro cytotoxicity against human drug sensitive (CCRF-CEM, K562) versus multidrug resistant leukaemia cell lines (K562-Tax, CEM-DNRBULK), colon cancer cells with normal $(+/+)$ or inactive (-/-) p53 oncosuppressor $\left(\right.$ HCT116p53 $3^{+/+}$, HCT116p53 ${ }^{-/}$), lung adenocarcinoma (A549), normal foetal lung (MRC-5) and foreskin (BJ) fibroblasts. Cytotoxic activity was evaluated after $72 \mathrm{hrs}$ of treatments using a cytotoxic MTT assay, based on reduction of yellow tetrazolium salt on blue formazan in mitochondria of living cellsM. The determined activities were expressed as $\mathrm{IC}_{50}$ values (concentrations leading to $50 \%$ decrease in cell survival).

As outlined in Table 2, compounds displayed only a mild activity against the above mentioned cell lines. The configurationally modified varitriol $\mathbf{5}$ as a mixture of $E / Z$-isomers (in the ratio 5:4) showed the most significant activities against the all tested cell lines, whereas varitriol 6a ( $E$-isomer) and its $Z$-analogue 7a showed much lower activities or were inactive. Interestingly, the difference in the geometry of the linker $\mathbf{6 a}, \mathbf{6 h}, \mathbf{6 k}$ ( $E$-isomers) vs $7 \mathbf{a}, 7 \mathbf{h}, 7 \mathbf{k}$, caused in general a slightly higher cytotoxic activities of $Z$-isomers (7a, $7 \mathbf{h}, \mathbf{7 k}$ ). The widest spectrum of activities from the set of analogues with differently substituted aromatic part, were 
displayed by compounds $6 \mathbf{e}$ (2,4-dimethoxy), $6 \mathbf{f}$ (2,5-dimethoxy), 6i (4-bromo). Majority of the tested compounds demonstrated the highest activities against human T-lymphoblastic leukaemia cell line CCRF-CEM and its multidrug resistant subline CEM-DNR-BULK overexpressing the multidrug resistant protein 1 (MRP-1), thus showing compounds activity in multidrug resistant cancers. Unexpectedly, the in vitro anticancer activity of synthetic varitriol and its analogues was dramatically lower than that reported for natural varitriol by Barrero et al., obtained from the tests against RXF 393, TD-47, SNB, DU-145, HL-60, CCRF-CEM, OVCAR-5, SNB-19 and COLO 205 cell lines. ${ }^{2}$ Thus, in order to prevent bias in methodology of testing or cell line selection, we decided to submit all prepared compounds 5, 6, 7 for further testing against the $\mathrm{NCI}_{60}$ cancer cell line panel at the developmental therapeutics program, Division of Cancer Treatment and Diagnosis, National Cancer Institute (DTP, Bethesda, USA). Surprisingly, neither synthetic (+)-varitriol nor the analogues 5, 6 and 7 exhibited expected $\mathrm{GI}_{50}$ when evaluated against $\mathrm{NCI}_{60}$ panel at a single $10 \mu \mathrm{M}$ concentration (see supporting information), thus confirming our primary data from MTT cytotoxic activity evaluation.

Table 2. Antiproliferative activities of synthesised varitriol analogues $\mathbf{5}, \mathbf{6 a - k}$ and $\mathbf{7 a}, \mathbf{b}, \mathbf{d}, \mathbf{h}, \mathbf{i}, \mathbf{k}$

\begin{tabular}{|c|c|c|c|c|c|c|c|c|c|}
\hline \multirow[t]{2}{*}{ Comp. } & \multicolumn{9}{|c|}{$\mathrm{IC}_{50} \mu \mathrm{M}^{\mathrm{a}}$} \\
\hline & $\begin{array}{l}\text { CCRF- } \\
\text { CEM }\end{array}$ & A549 & K562 & $\begin{array}{c}\text { K562- } \\
\text { Tax }\end{array}$ & $\begin{array}{c}\text { CEM-DNR- } \\
\text { BULK }\end{array}$ & $\begin{array}{c}\text { HCT116p53 } \\
+/+ \\
\end{array}$ & $\begin{array}{c}\text { HCT116p53 - } \\
\text { /- }\end{array}$ & MRC 5 & BJ \\
\hline $\begin{array}{c}5 \\
6 \mathbf{a}\end{array}$ & 45.3 & 67.1 & 107 & 84.8 & 115 & 76.3 & 104 & $>166$ & 150 \\
\hline$[(+)-\mathbf{1}]$ & 161 & $>166$ & $>166$ & $>166$ & 153 & $>166$ & $>166$ & 166 & $>166$ \\
\hline $7 \mathbf{a}$ & 121 & 163 & 158 & $>166$ & 132 & 111 & $>166$ & $>166$ & $>166$ \\
\hline $6 \mathbf{b}$ & 145 & $>166$ & $>166$ & $>166$ & 151 & $>166$ & $>166$ & 154 & $>166$ \\
\hline $7 b$ & 160 & $>166$ & $>166$ & $>166$ & 149 & $>166$ & $>166$ & 152 & $>166$ \\
\hline $6 c$ & 142 & $>166$ & $>166$ & $>166$ & 154 & $>166$ & $>166$ & 152 & $>166$ \\
\hline $6 d$ & 144 & $>166$ & $>166$ & 147 & 164 & $>166$ & $>166$ & $>166$ & $>166$ \\
\hline $7 d$ & 157 & $>166$ & $>166$ & 153 & $>166$ & $>166$ & $>166$ & 156 & $>166$ \\
\hline $6 e$ & 132 & $>166$ & 149 & 159 & 133 & 140 & 155 & $>166$ & $>166$ \\
\hline $6 f$ & 130 & $>166$ & 155 & $>166$ & 123 & 151 & 160 & $>166$ & $>166$ \\
\hline $6 \mathrm{~g}$ & 147 & $>166$ & $>166$ & $>166$ & 149 & $>166$ & $>166$ & 152 & $>166$ \\
\hline $6 h$ & 145 & $>166$ & $>166$ & 149 & $>166$ & 154 & $>166$ & $>166$ & $>166$ \\
\hline $7 \mathrm{~h}$ & 147 & $>166$ & $>166$ & 151 & 135 & $>166$ & 157 & 148 & $>166$ \\
\hline
\end{tabular}


Table 2 (continued)

\begin{tabular}{cccccccccc}
\hline Comp. & \multicolumn{10}{c}{$\mathrm{IC}_{50} \mu \mathrm{M}^{\mathrm{a}}$} \\
\hline & $\begin{array}{c}\text { CCRF- } \\
\text { CEM }\end{array}$ & A549 & K562 & $\begin{array}{c}\text { K562- } \\
\text { Tax }\end{array}$ & $\begin{array}{c}\text { CEM-DNR- } \\
\text { BULK }\end{array}$ & $\begin{array}{c}\text { HCT116p53 } \\
+/+\end{array}$ & $\begin{array}{c}\text { HCT116p53- } \\
/-\end{array}$ & MRC 5 & BJ \\
\hline $\mathbf{6 i}$ & 146 & $>166$ & $>166$ & 136 & $>166$ & 162 & 150 & 154 & $>166$ \\
$\mathbf{7 i}$ & 147 & $>166$ & $>166$ & 148 & $>166$ & $>166$ & $>166$ & $>166$ & $>166$ \\
$\mathbf{6 j}$ & 138 & $>166$ & 153 & $>166$ & 141 & 153 & $>166$ & $>166$ & $>166$ \\
$\mathbf{6 k}$ & 136 & $>166$ & $>166$ & $>166$ & 143 & $>166$ & $>166$ & $>166$ & $>166$ \\
$\mathbf{7 k}$ & 131 & 143 & 142 & 155 & 121 & 158 & 136 & $>166$ & 156 \\
\hline
\end{tabular}

${ }^{\mathrm{a}} \mathrm{IC}_{50}$ values in a 3-day MTT assay. Presented values are averages of at least three independent experiments, where standard deviations were typically within $25 \%$ of the average.

\section{Conclusions}

In summary, the varitriol analogues with modified aromatic part $\mathbf{6 a - k}$, geometry of the C-C double bond $\mathbf{7 a - c}, \mathbf{7 e}, \mathbf{f}, \mathbf{7 h}$ and $\mathbf{7 k}$, as well as a new 2-epimer $\mathbf{5}$ have been synthesised and evaluated for their in vitro antitumour activities against a number of selected human neoplastic cell lines and $\mathrm{NCI}_{60}$ cancer cell line panel at the Developmental Therapeutics Program, National Cancer Institute. All the compounds showed only mild activity, and compound $\mathbf{5}$ was the most active among the screened compounds. Though the compounds showed mild activity, the synthesis and screening of more analogues of varitriol with higher structural diversity or synthesis and exploration of bioactivity the other compounds (varioxirane $\mathbf{2}$, dihydroterrein $\mathbf{3}$, and varixanthone 4) isolated from a marine-derived strain of the fungus Emericella variecolor, would give scope for further work in this area.

Finally, the synthetic strategy has been proven to apply for rapid construction of varitriol analogues with variable side chain, linker and configuration of furanoside portion of the target molecule.

\section{Experimental Section}

General. Commercial reagents were used without further purification. All solvents were distilled before use. Hexanes refer to the fraction boiling at $60-65{ }^{\circ} \mathrm{C}$. Flash column liquid chromatography (FLC) was performed on silica gel Kieselgel 60 (40-63 $\mu$ m, 230-400 mesh) using Buchi Sepacore ${ }^{\circledR}$ preparative MPLC system and analytical thin-layer chromatography (TLC) was performed on aluminum plates pre-coated with either $0.2 \mathrm{~mm}$ (DC-Alufolien, Merck) 
or $0.25 \mathrm{~mm}$ silica gel $60 \mathrm{~F}_{254}$ (ALUGRAM ${ }^{\circledR}$ SIL G/UV ${ }_{254}$, Macherey-Nagel). The compounds were visualised by UV fluorescence and by dipping the plates in an aqueous $\mathrm{H}_{2} \mathrm{SO}_{4}$ solution of cerium sulphate/ammonium molybdate followed by charring with a heat-gun. Melting points were determined on a Büchi 540 apparatus and were not corrected. Optical rotations were measured with a JASCO P-2000 polarimeter and are given in units of $10^{-1} \mathrm{deg}^{-2} \mathrm{~cm}^{2} \cdot \mathrm{g}^{-1}$. High resolution mass spectra (HRMS) were recorded on a Q-Tof PremierTM mass spectrometer with nanoACQUITY UPLCTM (Waters), and are accurate to $\pm 3 \mathrm{ppm}$. FTIR spectra were obtained on a Nicolet 5700 spectrometer (Thermo Electron) equipped with a Smart Orbit (diamond crystal ATR) accessory, using the reflectance technique $\left(4000-400 \mathrm{~cm}^{-1}\right) .{ }^{1} \mathrm{H}$ and ${ }^{13} \mathrm{C}$ NMR spectra were recorded on either 300 (75) MHz MercuryPlus or 600 (150) MHz Unity Inova spectrometers from Varian. Chemical shifts $(\delta)$ are quoted in ppm and are referenced to the tetramethylsilane (TMS) as internal standard.

2,3-O-Isopropylidene-5- $\boldsymbol{O}$-tert-butyldimethylsilyl- $\gamma$-D-ribonolactone (12). To a solution of $\gamma$ D-ribonolactone $(1.5 \mathrm{~g}, 7.97 \mathrm{mmol})$ in dry DMF $(25 \mathrm{~mL})$ were successively added $\mathrm{Et}_{3} \mathrm{~N}(2.22$ $\mathrm{mL}, 15.94 \mathrm{mmol})$, TBDMSCl (1.92 g, $12.75 \mathrm{mmol})$ and DMAP (52 $\mathrm{mg}, 0.426 \mathrm{mmol})$. The resulting mixture was stirred at room temperature for $8 \mathrm{~h}$ than diluted with ether $(75 \mathrm{~mL})$ and extracted with water $(50 \mathrm{~mL})$. Aqueous phase was extracted with ether $(4 \times 30 \mathrm{~mL})$, combined extracts were washed with water $(3 \times 30 \mathrm{~mL})$, dried over $\mathrm{MgSO}_{4}$ and concentrated. Purification by flash chromatography (5\% EtOAc in hexanes) afforded the title compound $\mathbf{1 2}(2.29 \mathrm{~g}, 95 \%)$ as a white solid. Selected data: $R_{\mathrm{f}} 0.4\left(15 \%\right.$ AcOEt in hexanes), $[a]_{0}^{25}-48.8\left(c 0.221, \mathrm{CHCl}_{3}\right)$; IR (ATR): $v 2954$ (m), 2929 (m), 1772 (vs, CO), 1107 (vs), 1077 (vs), 837 (vs) cm ${ }^{-1} ;{ }^{1} \mathrm{H}$ NMR (300 $\left.\mathrm{MHz}, \mathrm{CDCl}_{3}\right): \delta$ 0.06, 0.08 (2 x s, $\left.6 \mathrm{H}, \mathrm{Si}\left(\mathrm{C}_{3}\right)_{2}\right), 0.88$ (s, 9H, $\mathrm{C}\left(\mathrm{C}_{3}\right)_{3}, 1.39,1.48$ (2 x s, $6 \mathrm{H}$, $\left.\mathrm{C}\left(\mathrm{CH}_{3}\right)_{2}\right), 3.80\left(\mathrm{dd}, 1 \mathrm{H}, \mathrm{A}\right.$ of $\left.\mathrm{ABX}, J_{5 \mathrm{~A}, 5 \mathrm{~B}}=11.3, J_{5 \mathrm{~A}, 4}=1.4 \mathrm{~Hz}, \mathrm{H}-5 \mathrm{~A}\right), 3.90(\mathrm{dd}, 1 \mathrm{H}, \mathrm{B}$ of $\mathrm{ABX}$, $\left.J_{5 \mathrm{~A}, 5 \mathrm{~B}}=11.3, J_{5 \mathrm{~B}, 4}=2.1 \mathrm{~Hz}, \mathrm{H}-5 \mathrm{~B}\right) 4.61\left(\mathrm{dd}, 1 \mathrm{H}, J_{5 \mathrm{~B}, 4}=1.8, J_{5 \mathrm{~A}, 4}=1.5 \mathrm{~Hz}, \mathrm{H}-4\right) 4.71\left(\mathrm{~d}, 1 \mathrm{H}, J_{2,3}\right.$ $=5.6 \mathrm{~Hz}, \mathrm{H}-2$ or H-3), $4.74\left(\mathrm{~d}, 1 \mathrm{H}, J_{2,3}=5.6 \mathrm{~Hz}, \mathrm{H}-2\right.$ or H-3 $) ;{ }^{13} \mathrm{C} \mathrm{NMR}\left(75 \mathrm{MHz}, \mathrm{CDCl}_{3}\right): \delta-$ 5.8, -5.6 (all q, $\left.\mathrm{Si}\left(\mathrm{C}_{3}\right)_{2}\right), 18.2\left(\mathrm{~s}, \underline{\mathrm{C}}\left(\mathrm{CH}_{3}\right)_{3}\right), 25.6,25.7,26.8$ (all q, $\left.\mathrm{C}\left(\underline{\mathrm{CH}}_{3}\right)_{2} \mathrm{C}\left(\underline{\mathrm{C}} \mathrm{H}_{3}\right)_{3}\right), 63.0$ (t, C5), 75.8, 78.4, 82.3 (all d, C-2, C-3, C-4), 113.0 (s, $\left.\underline{\mathrm{C}}\left(\mathrm{CH}_{3}\right)_{2}\right), 174.1$ (s, C-1). HRMS $\mathrm{m} / z$ Calc. for $\mathrm{C}_{14} \mathrm{H}_{26} \mathrm{NaO}_{5} \mathrm{Si}^{+}: 325.1442$, found $325.1393[\mathrm{M}+\mathrm{Na}]^{+}$.

2,5-Anhydro-6-deoxy-3,4- $O$-isopropylidene-1- $O$-tertbutyldimethylsilyl-L-allitol (13) and 2,5-anhydro-6-deoxy-3,4- $O$-isopropylidene-1- $O$-tertbutyldimethylsilyl-D-talitol (14). The lactone $12(1.9 \mathrm{~g}, 6.29 \mathrm{mmol})$ was dissolved in dry toluene $(120 \mathrm{~mL})$, cooled to $-78{ }^{\circ} \mathrm{C}$ under argon atmosphere and $10 \% \mathrm{w} / \mathrm{w}$ solution of DIBAL in hexanes $(13 \mathrm{mmol}, 28 \mathrm{~mL})$ was added dropwise. Reaction mixture was allowed to warm to $-50{ }^{\circ} \mathrm{C}$ and after $4 \mathrm{~h}$ was quenched with $\mathrm{HCl}$ $3 \mathrm{M}, 10 \mathrm{~mL})$. After warming to room temperature reaction was extracted between water $(100 \mathrm{~mL})$ and ether $(3 \times 30 \mathrm{~mL})$, combined organic layers were washed with brine, dried over $\mathrm{MgSO}_{4}$ and concentrated. The crude product was dissolved in dry dichloromethane $(60 \mathrm{~mL})$, cooled to $0{ }^{\circ} \mathrm{C}$, than DMAP $(2.3 \mathrm{~g}, 18.8 \mathrm{mmol})$ and $\mathrm{Ac}_{2} \mathrm{O}(1.2 \mathrm{ml}, 12.6 \mathrm{mmol})$ were added and the mixture was stirred for $12 \mathrm{~h}$. Resulting mixture was diluted with DCM $(100 \mathrm{~mL})$, washed with water $(50 \mathrm{~mL})$ and brine $(50 \mathrm{~mL})$, concentrated and used for subsequent methylation without further 
purification. Thus, $\mathrm{Me}_{3} \mathrm{Al}(2 \mathrm{M}$ in hexanes, $10 \mathrm{~mL}, 20 \mathrm{mmol}, 3$ equiv) was added dropwise to the crude oil in dry DCM $(35 \mathrm{~mL})$ at $-30{ }^{\circ} \mathrm{C}$. Reaction mixture was allowed to warm to $-18{ }^{\circ} \mathrm{C}$ and stirred overnight at this temperature. Resulting mixture was quenched with $5 \%$ w/w solution of citric acid $(100 \mathrm{~mL})$ extracted with ether $(3 \times 30 \mathrm{~mL})$, dried and concentrated. Separation using flash chromatography (2\% ether in hexanes) afforded $1.32 \mathrm{~g}(70 \%)$ of L-allo-diastereomer 13, $270 \mathrm{mg}$ of D-talo-diastereomer $14(15 \%)$ and $140 \mathrm{mg}(9 \%)$ of the mixture of both diastereomers (all were isolated as colourless liquids.)

2,5-Anhydro-6-deoxy-3,4- $\boldsymbol{O}$-isopropylidene-1- $\boldsymbol{O}$-tertbutyldimethylsilyl-L-allitol

(13).

Selected data: $R_{\mathrm{f}} 0.6$ (10\% AcOEt in hexanes), $[a]_{D}^{25}-5.5$ (c 0.217, $\mathrm{CHCl}_{3}$ ); IR (ATR): $v 2954$ (m), 2929 (s), 2858 (m), 1381 (m), 1253 (s), 1073 (s), 833 (s) cm ${ }^{-1} ;{ }^{1} \mathrm{H}$ NMR (300 MHz, CDCl ( $_{3}$ : $\delta$ 0.06, 0.07 (2 x s, 6H, Si $\left.\left(\mathrm{C}_{3}\right)_{2}\right), 0.90\left(\mathrm{~s}, 9 \mathrm{H}, \mathrm{C}\left(\mathrm{C}_{3}\right)_{3}, 1.28\right.$ (d, 3H, J5,6 $\left.=6.4 \mathrm{~Hz}, \mathrm{H}-6\right), 1.34$, $1.53\left(2 \mathrm{x} \mathrm{s}, 6 \mathrm{H}, \mathrm{C}\left(\mathrm{C}_{3}\right)_{2}\right), 3.72\left(\mathrm{dd}, 2 \mathrm{H}, J_{1,2}=3.9, J=0.8 \mathrm{~Hz}, \mathrm{H}-1\right), 3.95-4.01(\mathrm{~m}, 2 \mathrm{H}, \mathrm{H}-2, \mathrm{H}-5)$ $4.21\left(\mathrm{dd}, 1 \mathrm{H}, J_{3,4}=6.6, J=5.0 \mathrm{~Hz}, \mathrm{H}-3\right.$ or H-4) $4.64\left(\mathrm{dd}, 1 \mathrm{H}, J_{3,4}=6.7, J=3.6 \mathrm{~Hz}, \mathrm{H}-3\right.$ or H-4); ${ }^{13} \mathrm{C}$ NMR (75 MHz, $\left.\mathrm{CDCl}_{3}\right): \delta-5.4,-5.3$ (all q, $\left.\mathrm{Si}\left(\mathrm{CH}_{3}\right)_{2}\right), 18.4\left(\mathrm{~s}, \underline{\mathrm{C}}\left(\mathrm{CH}_{3}\right)_{3}\right), 19.1,25.5,25.9$, 27.5 (all q, C-6, $\left.\mathrm{C}\left(\underline{\mathrm{CH}}_{3}\right)_{2} \mathrm{C}\left(\mathrm{CH}_{3}\right)_{3}\right), 63.7$ (t, C-1), 80.6, 82.2, 84.4, 86.1 (all d, C-2, C-3, C-4, C5), 113.9 (s, $\left.\underline{\mathrm{C}}\left(\mathrm{CH}_{3}\right)_{2}\right)$. HRMS m/z Calc. for $\mathrm{C}_{15} \mathrm{H}_{30} \mathrm{NaO}_{4} \mathrm{Si}^{+}$: 325.1806, found 325.1703 $[\mathrm{M}+\mathrm{Na}]^{+}$.

2,5-Anhydro-6-deoxy-3,4-O-isopropylidene-1- $O$-tertbutyldimethylsilyl-D-talitol

(14).

Selected data: $R_{\mathrm{f}} 0.5$ (10\% AcOEt in hexanes), $[a]_{D}^{25}-9.1$ (c $0.219, \mathrm{CHCl}_{3}$ ); IR (ATR): $v 2954$ (m), 2929 (s), 2856 (m), 1379 (m), 1254 (s), 1086 (s), 834 (s) cm ${ }^{-1} ;{ }^{1} \mathrm{H}$ NMR (300 MHz, CDCl $)$ : $\delta$ 0.05, 0.06 (2 x s, 6H, Si $\left.\left(\underline{\mathrm{CH}}_{3}\right)_{2}\right), 0.89$ (s, 9H, C( $\left.\left.\mathrm{C}_{3}\right)_{3}\right), 1.27$ (d, 3H, J5,6 $\left.=6.4 \mathrm{~Hz}, \mathrm{H}-6\right), 1.36$, $1.51\left(2 \times \mathrm{s}, 6 \mathrm{H}, \mathrm{C}\left(\mathrm{CH}_{3}\right)_{2}\right), 3.69\left(\mathrm{~d}, 2 \mathrm{H}, J_{1,2}=4.0 \mathrm{~Hz}, \mathrm{H}-1\right), 4.04\left(\mathrm{t}, 1 \mathrm{H}, J_{1,2}=4.0 \mathrm{~Hz}, \mathrm{H}-2\right), 4.20$ $\left(\mathrm{dq}, 1 \mathrm{H}, J_{5,6}=6.4, J_{4,5}=4.1 \mathrm{~Hz}, \mathrm{H}-5\right), 4.58\left(\mathrm{dd}, 1 \mathrm{H}, J_{3.4}=6.1, J_{4,5}=4.0 \mathrm{~Hz}, \mathrm{H}-4\right), 4.81(\mathrm{dd}, 1 \mathrm{H}$, $\left.J_{3,4}=6.1, J_{2,3}=0.5 \mathrm{~Hz}, \mathrm{H}-3\right) ;{ }^{13} \mathrm{C}$ NMR $\left(75 \mathrm{MHz}, \mathrm{CDCl}_{3}\right): \delta-5.6,-5.5\left(\right.$ all q, $\left.\mathrm{Si}\left(\underline{\mathrm{CH}}_{3}\right)_{2}\right), 14.6$ (q, C-6) 18.1 (s, $\left.\underline{\mathrm{C}}\left(\mathrm{CH}_{3}\right)_{3}\right), 25.1$, 25.8, 26.3 (all q, $\left.\mathrm{C}\left(\underline{\mathrm{CH}}_{3}\right)_{2} \mathrm{C}\left(\underline{\mathrm{CH}}_{3}\right)_{3}\right)$, 64.7 (t, $\left.\mathrm{C}-1\right)$, 78.2, 82.8, 83.5, 84.1 (all d, C-2, C-3, C-4, C-5), 112.0 (s, $\underline{\mathrm{C}}\left(\mathrm{CH}_{3}\right)_{2}$ ). HRMS m/z Calc. for $\mathrm{C}_{15} \mathrm{H}_{34} \mathrm{NO}_{4} \mathrm{Si}^{+}$: 320.2252 , found $320.2096\left[\mathrm{M}+\mathrm{NH}_{4}\right]^{+}$.

2,5-Anhydro-6-deoxy-3,4- $\boldsymbol{O}$-isopropylidene-L-allitol (15). Tetrabutyl ammonium fluoride trihydrate $(1.815 \mathrm{~g}, 5.76 \mathrm{mmol})$ was added to the solution of the silyl ether $\mathbf{1 3}(870 \mathrm{mg}, 2.88$ $\mathrm{mmol})$ in THF (30 $\mathrm{mL})$ and stirred for $12 \mathrm{~h}$ at room temperature. Resulting mixture was than concentrated and purified by flash chromatography (15\% EtOAc in hexanes), yielding 15 (482 $\mathrm{mg}, 89 \%)$ as a colourless oil. Selected data: $R_{\mathrm{f}} 0.1\left(10 \%\right.$ AcOEt in hexanes), $[a]_{D}^{25}+8.5(c 0.743$, $\mathrm{CHCl}_{3}$ ); IR (ATR): $v 3334$ (s, OH), $2925(\mathrm{~m}), 1456(\mathrm{~m}), 1082(\mathrm{~s}), 1035(\mathrm{~s}) \mathrm{cm}^{-1}$; ${ }^{1} \mathrm{H}$ NMR (300 $\left.\mathrm{MHz}, \mathrm{CDCl}_{3}\right): \delta 1.32\left(\mathrm{~d}, 3 \mathrm{H}, J_{5,6}=6.4 \mathrm{~Hz}, \mathrm{H}-6\right), 1.34,1.54\left(2 \mathrm{x} \mathrm{s}, 6 \mathrm{H}, \mathrm{C}\left(\mathrm{C}_{3}\right)_{2}\right), 2.20(\mathrm{bs}, 1 \mathrm{H}$, $\mathrm{OH}), 3.67\left(\mathrm{dd}, 1 \mathrm{H}, \mathrm{A}\right.$ of $\left.\mathrm{ABX}, J_{1 \mathrm{~A}, 1 \mathrm{~B}}=11.7, J_{1 \mathrm{~A}, 2}=3.1 \mathrm{~Hz}, \mathrm{H}-1 \mathrm{~A}\right), 3.82(\mathrm{dd}, 1 \mathrm{H}, \mathrm{B}$ of $\mathrm{ABX}$, $\left.J_{1 \mathrm{~A}, 1 \mathrm{~B}}=11.9, J_{1 \mathrm{~B}, 2}=3.1 \mathrm{~Hz}, \mathrm{H}-1 \mathrm{~B}\right), 3.94-4.04(\mathrm{~m}, 2 \mathrm{H}, \mathrm{H}-2, \mathrm{H}-5), 4.23\left(\mathrm{dd}, 1 \mathrm{H}, J_{3,4}=6.9, J=5.2\right.$ Hz, H-3 or H-4) 4.62 (dd, $1 \mathrm{H}, J_{3,4}=7.0, J=4.5 \mathrm{~Hz}, \mathrm{H}-3$ or H-4); ${ }^{13} \mathrm{C}$ NMR $\left(75 \mathrm{MHz}, \mathrm{CDCl}_{3}\right): \delta$ 18.8, 25.4, 27.3 (all q, C-6, C( $\left.\underline{\mathrm{CH}}_{3}\right)_{2}$ ), 62.7 (t, C-1), 80.5, 81.6, 84.1, 86.1 (all d, C-2, C-3, C-4, C-5), $114.7\left(\mathrm{~s}, \underline{\mathrm{C}}\left(\mathrm{CH}_{3}\right)_{2}\right)$. HRMS m/z Calc. for $\mathrm{C}_{9} \mathrm{H}_{17} \mathrm{O}_{4}{ }^{+}: 189.1121$, found $189.1109[\mathrm{M}+\mathrm{H}]^{+}$. 
2,5-Anhydro-6-deoxy-3,4- $\boldsymbol{O}$-isopropylidene-D-talitol (17). A solution of 14 (290 mg, 0.96 $\mathrm{mmol})$ and tetrabutyl ammonium fluoride trihydrate $(605 \mathrm{~g}, 1.92 \mathrm{mmol})$ in THF $(10 \mathrm{~mL})$ was stirred for $12 \mathrm{~h}$ at room temperature. Resulting mixture was concentrated and purified by flash chromatography (15\% EtOAc in hexanes), providing title compound $\mathbf{1 7}(168 \mathrm{mg}, 93 \%)$ as a colourless oil. Selected data: $R_{\mathrm{f}} 0.1$ (10\% AcOEt in hexanes), $[a]_{D}^{25}+5.0$ (c 0.240, $\mathrm{CHCl}_{3}$ ); IR (ATR): v 3412 (m, OH), 2986 (m), 2936 (m), 1732 (m), 1374 (s), 1208 (vs), 1032 (vs), 872 (vs) $\mathrm{cm}^{-1} ;{ }^{1} \mathrm{H}$ NMR $\left(300 \mathrm{MHz}, \mathrm{CDCl}_{3}\right): \delta 1.32\left(\mathrm{~d}, 3 \mathrm{H}, J_{5,6}=6.3 \mathrm{~Hz}, \mathrm{H}-6\right), 1.35,1.52(2 \times \mathrm{s}, 6 \mathrm{H}$, $\left.\mathrm{C}\left(\mathrm{CH}_{3}\right)_{2}\right), 2.12$ (bs, 1H, OH), 3.60 (bs, 2H, H-1), 4.04-4.16 (m, 2H), 4.57-4.65 (m, $\left.2 \mathrm{H}\right) ;{ }^{13} \mathrm{C}$ NMR (75 MHz, $\left.\mathrm{CDCl}_{3}\right): \delta 14.2$ (q, C-6), 25.1, 26.3 (all q, C( $\left.\left.\underline{\mathrm{CH}}_{3}\right)_{2}\right), 61.7$ (t, C-1), 76.6, 82.3, 82.7, 84.1 (all d, C-2, C-3, C-4, C-5), 112.5 (s, $\underline{\mathrm{C}}\left(\mathrm{CH}_{3}\right)_{2}$ ). HRMS $\mathrm{m} / z$ Calc. for $\mathrm{C}_{9} \mathrm{H}_{17} \mathrm{O}_{4}{ }^{+}$: 189.1121, found $189.1127[\mathrm{M}+\mathrm{H}]^{+}$.

\section{2,5-Anhydro-1,6-dideoxy-3,4- $O$-isopropylidene-1-(1-phenyl-1H-tetrazol-5-ylsulfanyl)-L-}

allitol (16). 1-Phenyl- $1 H$-tetrazol-5-thiol $(3.28 \mathrm{~g}, 18.41 \mathrm{mmol}, 2.1$ equiv) was added to the solution of 15 (1.65 g, $8.77 \mathrm{mmol})$ in THF ( $80 \mathrm{~mL})$ and mixture was cooled to $0{ }^{\circ} \mathrm{C}$. Then $\mathrm{PPh}_{3}$ (3.45 mg, $13.15 \mathrm{mmol}, 1.5$ equiv) and DIAD (3.11 mL, $15.79 \mathrm{mmol}, 1.8$ equiv) were consecutively added. After stirring for $1 \mathrm{~h}$, the reaction mixture was extracted between ether $(2 \mathrm{x}$ $50 \mathrm{~mL})$ and brine $(50 \mathrm{~mL})$. Combined organic layer was dried over $\mathrm{MgSO}_{4}$, concentrated and purified by flash chromatography (10\% EtOAc in hexanes). Sulfide $\mathbf{1 6}$ was obtained as a colourless oil (2.6 g, 85\%). HRMS $m / z$ Calc. for $\mathrm{C}_{16} \mathrm{H}_{20} \mathrm{~N}_{4} \mathrm{NaO}_{3} \mathrm{~S}^{+}$: 371.1148, found 371.1187 $[\mathrm{M}+\mathrm{Na}]+$. The physical and spectral data of 16 were in accord with the literature. ${ }^{7 \mathrm{c}}$

2,5-Anhydro-1,6-dideoxy-3,4-O-isopropylidene-1-(1-phenyl-1H-tetrazol-5-ylsulfanyl)-Dtalitol (18). Prepared as above from 17 (140 mg, $0.75 \mathrm{mmol})$, PTSH (279 mg, $1.56 \mathrm{mmol})$, DIAD (264 $\mu \mathrm{l}, 1.34 \mathrm{mmol})$. Yield: $256 \mathrm{mg}$ (94\%, colourless oil). Selected data: $R_{\mathrm{f}} 0.6(50 \%$ AcOEt in hexanes), $[a]_{D}^{25}+24.9$ ( $\left.0.205, \mathrm{CHCl}_{3}\right)$; IR (ATR): $v 2982$ (m), 2934 (m), 1596 (m), 1499 (vs), 1382 (vs), 1084 (vs), 1012 (vs), 761 (vs) cm ${ }^{-1} ;{ }^{1} \mathrm{H}$ NMR (300 MHz, $\mathrm{CDCl}_{3}$ ): $\delta 1.29$ (d, $\left.3 \mathrm{H}, J_{5,6}=6.3 \mathrm{~Hz}, \mathrm{H}-6\right), 1.34,1.49\left(2 \mathrm{x} \mathrm{s}, 6 \mathrm{H}, \mathrm{C}\left(\mathrm{CH}_{3}\right)_{2}\right), 3.53\left(\mathrm{~d}, 2 \mathrm{H}, J_{1,2}=7.6 \mathrm{~Hz}, \mathrm{H}-1\right), 4.07$ (dq, $\left.1 \mathrm{H}, J_{5,6}=6.3, J_{4,5}=3.5 \mathrm{~Hz}, \mathrm{H}-5\right), 4.35\left(\mathrm{t}, 1 \mathrm{H}, J_{1,2}=7.7 \mathrm{~Hz}, \mathrm{H}-2\right), 4.65\left(\mathrm{dd}, 1 \mathrm{H}, J_{3,4}=6.0, J_{4,5}=\right.$ $3.4 \mathrm{~Hz}, \mathrm{H}-4), 4.70\left(\mathrm{dd}, 1 \mathrm{H}, J_{3,4}=6.1, J_{2,3}=0.5 \mathrm{~Hz}, \mathrm{H}-3\right), 7.53-7.60(\mathrm{~m}, 5 \mathrm{H}, \mathrm{Ph}) ;{ }^{13} \mathrm{C} \mathrm{NMR}(75$ $\mathrm{MHz}, \mathrm{CDCl}_{3}$ ): $\delta 13.7$ (q, C-6), 25.2, 26.3 (all q, $\mathrm{C}\left(\underline{\mathrm{CH}}_{3}\right)_{2}$ ), 33.7 (t, C-1), 76.3, 82.1, 82.2, 84.8 (all d, C-2, C-3, C-4, C-5), 112.8 (s, $\underline{\mathrm{C}}\left(\mathrm{CH}_{3}\right)_{2}$ ), 123.9, 129.8, 130.2 (all d, Ph), 133.5, 153.9 (all $\mathrm{s}, i$-Ph, $i$-Tetr). HRMS $m / z$ Calc. for $\mathrm{C}_{16} \mathrm{H}_{20} \mathrm{~N}_{4} \mathrm{NaO}_{3} \mathrm{~S}^{+}: 371.1148$, found $371.1177[\mathrm{M}+\mathrm{Na}]^{+}$.

2,5-Anhydro-1,6-dideoxy-3,4- $O$-isopropylidene-1-(1-phenyl-1H-tetrazol-5-ylsulfonyl)-Lallitol (8) was prepared from sulfide 16 as described. ${ }^{7 \mathrm{c}}$

\section{2,5-Anhydro-1,6-dideoxy-3,4-O-isopropylidene-1-(1-phenyl-1H-tetrazol-5-ylsulfonyl)-D-}

talitol (19). Prepared by $\mathrm{Mo}(\mathrm{IV}) / \mathrm{H}_{2} \mathrm{O}_{2}$ oxidation of sulfide $18(50 \mathrm{mg}, 0.137 \mathrm{mmol})$ according to the described procedure.7c Yield: $49 \mathrm{mg}$ (91\%, white solid). Selected data: m.p. 132-134 ${ }^{\circ} \mathrm{C} ; R_{\mathrm{f}}$ 0.6 (50\% AcOEt in hexanes), $[a]_{D}^{25}+82.3$ ( $\left.c 0.147, \mathrm{CHCl}_{3}\right)$; IR (ATR): $v 2990$ (m), 2971 (m), 2934 (m), 1496 (s), 1349 (vs), 1152 (vs), 1075 (vs), 772 (vs) cm ${ }^{-1} ;{ }^{1} \mathrm{H} \mathrm{NMR} \mathrm{(300} \mathrm{MHz,} \mathrm{CDCl}{ }_{3}$ ): $\delta 1.07\left(\mathrm{~d}, 3 \mathrm{H}, J_{5,6}=6.3 \mathrm{~Hz}, \mathrm{H}-6\right), 1.31,1.45\left(2 \mathrm{x} \mathrm{s}, 6 \mathrm{H}, \mathrm{C}\left(\mathrm{C}_{3}\right)_{2}\right), 3.48\left(\mathrm{dd}, 1 \mathrm{H}, \mathrm{A}\right.$ of ABX, $J_{1 \mathrm{~A}, 1 \mathrm{~B}}$ $\left.=15, J_{1 \mathrm{~A}, 2}=3.5 \mathrm{~Hz}, \mathrm{H}-1 \mathrm{~A}\right), 3.80\left(\mathrm{dq}, 1 \mathrm{H}, J_{5,6}=6.2, J_{4,5}=3.1 \mathrm{~Hz}, \mathrm{H}-5\right), 4.18(\mathrm{dd}, 1 \mathrm{H}, \mathrm{B}$ of ABX, 
$\left.J_{1 \mathrm{~A}, 1 \mathrm{~B}}=15, J_{1 \mathrm{~B}, 2}=10.8 \mathrm{~Hz}, \mathrm{H}-1 \mathrm{~B}\right), 4.55-4.63(\mathrm{~m}, 3 \mathrm{H}, \mathrm{H}-2, \mathrm{H}-3, \mathrm{H}-4), 7.54-7.66(\mathrm{~m}, 5 \mathrm{H}, \mathrm{Ph}) ;{ }^{13} \mathrm{C}$ NMR (75 MHz, $\left.\mathrm{CDCl}_{3}\right): \delta 13.2$ (q, C-6), 25.0, 26.1 (all q, $\left.\mathrm{C}\left(\underline{\mathrm{CH}}_{3}\right)_{2}\right), 55.9$ (t, C-1), 76.2, 78.4, 81.8, 84.8 (all d, C-2, C-3, C-4, C-5), 113.1 (s, $\left.\underline{\mathrm{C}}\left(\mathrm{CH}_{3}\right)_{2}\right), 125.7,129.4,131.4$ (all d, Ph), 133.0, 153.8 (all s, $i$-Ph, $i$-Tetr). HRMS $m / z$ Calc. for $\mathrm{C}_{16} \mathrm{H}_{20} \mathrm{~N}_{4} \mathrm{NaO}_{5} \mathrm{~S}^{+}: 403.1047$, found 403.1063 $[\mathrm{M}+\mathrm{Na}]^{+}$.

\section{General procedure for the preparation of varitriol analogues}

The solution of sulfone (8 or 19, 1 equiv) and aldehyde $(\mathbf{9}, 5$ equiv) in dry DME (10 mL/100 mg of sulfone) was cooled to $-30{ }^{\circ} \mathrm{C}$ under argon atmosphere. Potassium hexamethyldisilazane $(0.5$ $\mathrm{M}$ in toluene, 1.6 equiv) was added dropwise and the resulting mixture was allowed to warm slowly to rt and stirred overnight. The reaction was then quenched by addition of water $(0.5 \mathrm{~mL})$ and concentrated in vacuo. The crude product of the olefination was dissolved in THF (20 $\mathrm{mL} / 100 \mathrm{mg}$ of sulfone) and $1 \mathrm{M}$ aqueous $\mathrm{HCl}(20 \mathrm{~mL} / 100 \mathrm{mg}$ of sulfone) was added. The reaction mixture was stirred at $\mathrm{rt}$ until full conversion (TLC control, 3-12h). Mixture was neutralised with solid $\mathrm{Na}_{2} \mathrm{CO}_{3}$ and extracted with ethyl acetate. The combined organic layers were dried over anhydrous sodium sulfate, filtered, and concentrated in vacuo. The crude product was purified by flash chromatography on silica gel. Combined yields of olefins 5, 6, 7 as well as the yields of isolated pure isomers 6, 7 are given in the Table 1. Deprotection of hydroxyl groups in the compounds 5, 6a, 7a was carried out as follows: the crude product was dissolved in $\mathrm{MeOH}$ $(6 \mathrm{~mL})$ and freshly prepared sodium methoxide $(0.6 \mathrm{M}$ in $\mathrm{MeOH}, 2.1 \mathrm{~mL})$ was added. The mixture was allowed to stir for $4 \mathrm{~h}$, by which time TLC (EtOAc/hexanes, 3:7) showed complete conversion of the starting material. The residue was dissolved in THF (20 mL) and $1 \mathrm{M}$ aqueous $\mathrm{HCl}(20 \mathrm{~mL})$ and stirred at $\mathrm{rt}$ for $5 \mathrm{~h}$. The work-up followed as above.

2-Epi-varitriol (5). Yield: $62 \mathrm{mg}\left(78 \%\right.$, E/Z-mixture in the ratio 5:4 by ${ }^{1} \mathrm{H} \mathrm{NMR}$ as a slightly yellow oil); $R_{\mathrm{f}} 0.3$ (50\% AcOEt in hexanes), $[a]_{D}^{25}+34.5$ (c 0.568, MeOH); IR (ATR): $v 3390$ (m, $\mathrm{OH}), 2933$ (m), 1722 (m), 1577 (s), 1262 (vs), 1000 (vs), 752 (s) cm ${ }^{-1}$; ${ }^{1} \mathrm{H}$ NMR (300 MHz, $\left.\left(\mathrm{CD}_{3}\right)_{2} \mathrm{CO}\right): \delta 1.13\left(\mathrm{~d}, 3 \mathrm{H}, J_{\mathrm{Me}, 2}=6.5 \mathrm{~Hz}, \mathrm{Me}\right.$, minor), $1.22\left(\mathrm{~d}, 3 \mathrm{H}, J_{\mathrm{Me}, 2}=6.5 \mathrm{~Hz}, \mathrm{Me}\right.$, major), 3.82 (s, 3H, OMe, major), 3.83 (s, 3H, OMe, minor), 3.83-4.73 (m, 6H, H-2, H-3, H-4, H-5, $\left.\mathrm{OCH}_{2}\right), 5.78\left(\mathrm{dd}, 1 \mathrm{H}, J_{1^{\prime}, 2^{\prime}}=11.4, J_{1^{\prime}, 5}=9.7 \mathrm{~Hz}, \mathrm{H}-1^{\prime}\right.$ minor), $6.21\left(\mathrm{dd}, 1 \mathrm{H}, J_{1^{\prime}, 2^{\prime}}=15.7, J_{1^{\prime}, 5}=\right.$ $6.8 \mathrm{~Hz}, \mathrm{H}-1^{\prime}$, major), 6.86-7.26 (m, 4H, Ph, H-2') ${ }^{13} \mathrm{C} \mathrm{NMR}\left(75 \mathrm{MHz},\left(\mathrm{CD}_{3}\right)_{2} \mathrm{CO}\right): \delta 16.4,16.6$ (all q, Me), 56.4 (t, $\mathrm{CH}_{2} \mathrm{OH}$ ), 56.9, 57.0 (all q, OMe), 57.0 (t, $\mathrm{CH}_{2} \mathrm{OH}$ ), 74.9, 75.0, 77.9, 78.1, 78.7, 79.7, 80.0, 84.0 (all d, C-2, C-3, C-4, C-5), 111.5, 111.7 (d, C-6'), 128.8, 129.2 (s, C-4'), 120.3, 123.8, 130.0, 130.1, 130.3, 132.9, 134.1, 135.0 (all d, C-1', C-2’, C-7', C-8'), 139.7, 140.1 (s, C-3'), 159.8, 159.9 (s, C-5'). HRMS m/z Calc. for $\mathrm{C}_{15} \mathrm{H}_{20} \mathrm{NaO}_{5}{ }^{+}: 303.1203$, found 303.1002 $[\mathrm{M}+\mathrm{Na}]^{+}$.

$\boldsymbol{E}$-Varitriol (6a). Yield: $45 \mathrm{mg}$ (56\%, white solid). The physical and spectral data of $6 \mathbf{6}$ were in accord with the literature. ${ }^{7 \mathrm{c}}$

Z-Varitriol (7a). Yield: $11 \mathrm{mg}$ (14\%, white solid); m.p. 126-130 ${ }^{\circ} \mathrm{C}, R_{\mathrm{f}} 0.2(50 \%$ AcOEt in hexanes), $[a]_{D}^{25}+22.5$ ( $\left.c 0.129, \mathrm{MeOH}\right)$; IR (ATR): $v 3384(\mathrm{~m}, \mathrm{OH}), 2962(\mathrm{~m}), 1745(\mathrm{w}), 1577$ (s), 1262 (vs), 1072 (vs), 1014 (vs), 775 (s) cm ${ }^{-1} ;{ }^{1} \mathrm{H}$ NMR (300 MHz, $\left.\left(\mathrm{CD}_{3}\right)_{2} \mathrm{CO}\right): \delta 1.21$ (d, 3H, 
$\left.J_{\mathrm{Me}, 2}=6.1 \mathrm{~Hz}, \mathrm{Me}\right), 3.62-3.70(\mathrm{~m}, 2 \mathrm{H}), 3.84-3.92(\mathrm{~m}, 6 \mathrm{H}), 4.28\left(\mathrm{dd}, 1 \mathrm{H}, J_{1^{\prime}, 5}=9.6, J_{4,5}=5.5 \mathrm{~Hz}\right.$, $\mathrm{H}-5), 4.59\left(\mathrm{dd}, 1 \mathrm{H}, J_{\mathrm{A}, \mathrm{B}}=11.4, J_{\mathrm{A}, \mathrm{OH}}=4.7 \mathrm{~Hz}, \underline{\mathrm{C}}_{\mathrm{A}} \mathrm{H}_{\mathrm{B}} \mathrm{OH}\right), 4.67\left(\mathrm{dd}, 1 \mathrm{H}, J_{\mathrm{A}, \mathrm{B}}=11.4, J_{\mathrm{B}, \mathrm{OH}}=4.5\right.$ $\left.\mathrm{Hz}, \mathrm{CH}_{\mathrm{A}} \underline{\mathrm{H}}_{\mathrm{B}} \mathrm{OH}\right), 5.74\left(\mathrm{dd}, 1 \mathrm{H}, J_{1^{\prime}, 2^{\prime}}=11.4, J_{1^{\prime}, 5}=9.7 \mathrm{~Hz}, \mathrm{H}-1^{\prime}\right), 6.87-6.98$ (m, 3H, H-2', H-6', $\left.\mathrm{H}-8^{\prime}\right), 7.23\left(\mathrm{t}, 1 \mathrm{H}, J=8.0 \mathrm{~Hz}, \mathrm{H}-7^{\prime}\right) ;{ }^{13} \mathrm{C} \mathrm{NMR}\left(75 \mathrm{MHz},\left(\mathrm{CD},{ }_{3}\right)_{2} \mathrm{CO}\right): \delta 20.6$ (q, Me), 56.9 (q, $\mathrm{OMe}$ ), 57.7 (t, $\mathrm{CH}_{2} \mathrm{OH}$ ), 77.7, 78.4, 81.2, 81.4 (all d, C-2, C-3, C-4, C-5), 111.8 (d, C-6'), 129.3 (s, C-4'), 123.7, 130.1, 132.9, 134.2 (all d, C-1', C-2', C-7', C-8'), 139.5 (s, C-3’), 159.9 (s, C$\left.5^{\prime}\right)$. HRMS $m / z$ Calc. for $\mathrm{C}_{15} \mathrm{H}_{20} \mathrm{NaO}_{5}^{+}: 303.1203$, found $303.1103[\mathrm{M}+\mathrm{Na}]^{+}$.

$\boldsymbol{E}$-(2S,3R,4S,5R)-2-Methyl-5-styryltetrahydrofuran-3,4-diol (6b). Yield: $34 \mathrm{mg}$ (53\%, white solid); m.p. $72-74{ }^{\circ} \mathrm{C}, R_{\mathrm{f}} 0.2$ (50\% AcOEt in hexanes), $[a]_{D}^{25}+49.54$ (c 0.131, MeOH); IR (ATR): v 3311(m, OH), 2976 (m), 1450 (m), 1123 (s), 1055 (vs), 964 (vs) cm ${ }^{-1} ;{ }^{1} \mathrm{H}$ NMR (300 MHz, $\left(\mathrm{CD}_{3}\right)_{2} \mathrm{CO}$ ): $\delta 1.27$ (d, 3H, $J_{\mathrm{Me}, 2}=6.3 \mathrm{~Hz}, \mathrm{Me}$ ), 3.70 (“t”, $1 \mathrm{H}, J=5.7 \mathrm{~Hz}, \mathrm{H}-3$ or H-4), 3.84 ("qi", $\left.1 \mathrm{H}, J_{\mathrm{Me}, 2}=6.1, J_{2,3}=5.8 \mathrm{~Hz}, \mathrm{H}-2\right) 3.90$ (“t”, $1 \mathrm{H}, J=5.7 \mathrm{~Hz}, \mathrm{H}-3$ or H-4), 4.26 ("cbt”, $1 \mathrm{H}, J_{1^{\prime}, 5}=$ $\left.6.3, J_{4,5}=5.7 \mathrm{~Hz}, \mathrm{H}-5\right), 6.33\left(\mathrm{dd}, 1 \mathrm{H}, J_{1^{\prime}, 2^{\prime}}=15.9, J_{1^{\prime}, 5}=6.5 \mathrm{~Hz}, \mathrm{H}-1^{\prime}\right), 6.67\left(\mathrm{~d}, 1 \mathrm{H}, J_{1^{\prime}, 2^{\prime}}=15.9\right.$ $\left.\mathrm{Hz}, \mathrm{H}-2^{\prime}\right), 7.20-7.36$ (m, 3H, Ph), 7.42-7.48 (m, 2H, Ph); $\left.{ }^{13} \mathrm{C} \mathrm{NMR} \mathrm{(75} \mathrm{MHz,}\left(\mathrm{CD}_{3}\right)_{2} \mathrm{CO}\right): \delta 20.5$ (q, Me), 77.5, 78.1, 81.1, 86.1 (all d, C-2, C-3, C-4, C-5), 128.3, 129.3, 130.4, 131.1, 132.5 (all d, C-1', C-2', Ph), 138.9 (s, i-Ph). HRMS m/z Calc. for $\mathrm{C}_{13} \mathrm{H}_{16} \mathrm{NaO}_{3}{ }^{+}:$243.0992, found 243.0871 $[\mathrm{M}+\mathrm{Na}]^{+}$.

$Z$-(2S,3R,4S,5R)-2-Methyl-5-styryltetrahydrofuran-3,4-diol (7b). Yield: $17 \mathrm{mg}$ (26\%, white solid); m.p. $62-64{ }^{\circ} \mathrm{C}, R_{\mathrm{f}} 0.3$ (50\% AcOEt in hexanes), $[a]_{D}^{25}-42.771$ (c 0.170, MeOH); IR (ATR): v 3373 (m, OH), 2970 (m), 1446 (m), 1085 (vs), 979 (vs), 777 (vs) cm ${ }^{-1}$; ${ }^{1} \mathrm{H}$ NMR (300 MHz, $\left.\left(\mathrm{CD}_{3}\right)_{2} \mathrm{CO}\right): \delta 1.25\left(\mathrm{~d}, 3 \mathrm{H}, J_{\mathrm{Me}, 2}=6.1 \mathrm{~Hz}, \mathrm{Me}\right), 3.70$ (“'t”, $1 \mathrm{H}, J_{2,3}=5.8, J_{3,4}=5.5 \mathrm{~Hz}, \mathrm{H}-3$ ), 3.77 ("qii", $1 \mathrm{H}, J_{\mathrm{Me}, 2}=6.1, J_{2,3}=5.8 \mathrm{~Hz}, \mathrm{H}-2$ ) 3.95 ("t", $1 \mathrm{H}, J_{3,4}=5.5, J_{4,5}=5.3 \mathrm{~Hz}, \mathrm{H}-4$ ), 4.56 (ddd, $\left.1 \mathrm{H}, J_{1^{\prime}, 5}=9.3, J_{4,5}=5.3, J=0.7 \mathrm{~Hz}, \mathrm{H}-5\right), 5.67\left(\mathrm{dd}, 1 \mathrm{H}, J_{1^{\prime}, 2^{\prime}}=11.7, J_{1^{\prime}, 5}=9.3 \mathrm{~Hz}, \mathrm{H}-1^{\prime}\right), 6.67(\mathrm{~d}$, $\left.1 \mathrm{H}, J_{1^{\prime}, 2^{\prime}}=11.7 \mathrm{~Hz}, \mathrm{H}-2^{\prime}\right), 7.22-7.39(\mathrm{~m}, 3 \mathrm{H}, \mathrm{Ph}), 7.44-7.50(\mathrm{~m}, 2 \mathrm{H}, \mathrm{Ph}) ;{ }^{13} \mathrm{C} \mathrm{NMR}(75 \mathrm{MHz}$, $\left(\mathrm{CD}_{3}\right)_{2} \mathrm{CO}$ ): $\delta 20.5$ (q, Me), 78.1, 78.6, 80.9, 81.3 (all d, C-2, C-3, C-4, C-5), 129.1, 129.9, 130.9, 133.3, 134.1 (all d, C-1', C-2', Ph), 138.34 (s, $i$-Ph). HRMS m/z Calc. for $\mathrm{C}_{13} \mathrm{H}_{16} \mathrm{NaO}_{3}{ }^{+}$: 243.0992, found $243.0947[\mathrm{M}+\mathrm{Na}]^{+}$.

$\boldsymbol{E}$-(2S,3R,4S,5R)-5-(2-Methoxystyryl)-2-methyltetrahydrofuran-3,4-diol (6c). Yield: $35 \mathrm{mg}$ (49\%); m.p. $130-131{ }^{\circ} \mathrm{C}, R_{\mathrm{f}} 0.1$ (50\% AcOEt in hexanes), $[a]_{D}^{25}+48.3$ (c 0.197, MeOH); IR (ATR): v 3337 (m, OH), 2912 (m), 1596 (m), 1489 (s), 1244 (vs), 968 (vs), 764 (vs) cm ${ }^{-1} ;{ }^{1} \mathrm{H}$ NMR (300 MHz, (CD $\left.\mathrm{CD}_{3} \mathrm{OD}\right): \delta 1.31$ (d, 3H, $\left.J_{\mathrm{Me}, 2}=6.3 \mathrm{~Hz}, \mathrm{Me}\right), 3.69$ (“t”, $1 \mathrm{H}, J=5.6 \mathrm{~Hz}, \mathrm{H}-3$ or $\mathrm{H}-4$ ), 3.83 (s, 3H, OMe) 3.85-3.95 (m, 2H, H-2, H-3 or H-4), 4.30 (“t”, $1 \mathrm{H}, J_{1^{\prime}, 5}=7.1, J_{4,5}=5.6$ $\mathrm{Hz}, \mathrm{H}-5), 4.61$ (bs, 2H, 2 x OH), 6.22 (dd, 1H, $\left.J_{1^{\prime}, 2^{\prime}}=16, J_{1^{\prime}, 5}=7.1 \mathrm{~Hz}, \mathrm{~Hz}, \mathrm{H}-1^{\prime}\right), 6.86-7.02$ (m, $\left.3 \mathrm{H}, \mathrm{H}-2^{\prime}, \mathrm{Ph}\right), 7.22$ (dt, 1H, $\left.J=7.7, J=1.6 \mathrm{~Hz}, \mathrm{Ph}\right), 7.45(\mathrm{dd}, 1 \mathrm{H}, J=7.6, J=1.4 \mathrm{~Hz}, \mathrm{Ph}) ;{ }^{13} \mathrm{C}$ NMR (75 MHz, CD $\mathrm{CD}_{3}$ ): $\delta 19.6$ (q, Me), 56.0 (OMe), 76.9, 77.6, 80.6, 86.2 (all d, C-2, C-3, C4, C-5), 112.1, 121.7, 127.9, 128.3, 129.5, 130.1(all d, C-1', C-2', Ph), 126.7, 158.3 (all s, $i$-Ph). HRMS $m / z$ Calc. for $\mathrm{C}_{14} \mathrm{H}_{18} \mathrm{NaO}_{4}{ }^{+}: 273.1097$, found $273.0922[\mathrm{M}+\mathrm{Na}]^{+}$.

$\boldsymbol{E}$-(2S,3R,4S,5R)-5-(4-Methoxystyryl)-2-methyltetrahydrofuran-3,4-diol (6d). Yield: $44 \mathrm{mg}$ (41\%); $R_{\mathrm{f}} 0.1$ (50\% AcOEt in hexanes), $[a]_{D}^{25}+30.5$ (c 0.203, MeOH); IR (ATR): $v 3367$ (m, $\mathrm{OH}), 2968$ (w), 2930 (w), 1705 (m), 1605 (s), 1511 (vs), 1245 (vs), 1027 (vs), 967 (s) cm cm $^{-1} \mathrm{H}$ 
NMR (300 MHz, $\left.\left(\mathrm{CD}_{3}\right)_{2} \mathrm{CO}\right): \delta 1.26\left(\mathrm{~d}, 3 \mathrm{H}, J_{\mathrm{Me}, 2}=6.3 \mathrm{~Hz}, \mathrm{Me}\right), 1.96$ (s, 2H, 2 x OH) 3.68 (" $\mathrm{t}$ ", $1 \mathrm{H}, J=5.7 \mathrm{~Hz}, \mathrm{H}-3$ or H-4), 3.76-3.92 (m, 5H, H-2, H-3 or H-4, OMe), 4.22 ("bt", $1 \mathrm{H}, J=6.1$ $\mathrm{Hz}, \mathrm{H}-5), 6.15\left(\mathrm{dd}, 1 \mathrm{H}, J_{1^{\prime}, 2^{\prime}}=15.9, J_{1^{\prime}, 5}=6.8 \mathrm{~Hz}, \mathrm{H}-1^{\prime}\right), 6.59$ (d, 1H, $\left.J_{1^{\prime}, 2^{\prime}}=15.9 \mathrm{~Hz}, \mathrm{H}-2^{\prime}\right), 6.89$ $(\mathrm{d}, 2 \mathrm{H}, J=8.8 \mathrm{~Hz}, \mathrm{Ph}), 7.38(\mathrm{~d}, 2 \mathrm{H}, J=8.7 \mathrm{~Hz}, \mathrm{Ph}) ;{ }^{13} \mathrm{C} \mathrm{NMR}\left(75 \mathrm{MHz},\left(\mathrm{CD}_{3}\right)_{2} \mathrm{CO}\right): \delta 20.5(\mathrm{q}$, Me), 56.5 (q, OMe), 77.5, 78.1, 81.0, 86.3 (all d, C-2, C-3, C-4, C-5), 115.8 (d, C-5', C-7'), 128.6 (d, C-1'or C-2'), 129.5 (d, C-4', C-8’), 131.4 (s, C-3’), 132.3 (d, C-1'or C-2'), 161.3 (s, C$\left.6^{\prime}\right)$. HRMS $m / z$ Calc. for $\mathrm{C}_{14} \mathrm{H}_{18} \mathrm{NaO}_{4}^{+}: 273.1097$, found $273.1056[\mathrm{M}+\mathrm{Na}]^{+}$.

Z-(2S,3R,4S,5R)-5-(4-Methoxystyryl)-2-methyltetrahydrofuran-3,4-diol (7d). Yield: $19 \mathrm{mg}$ (18\%); m.p. $124-126{ }^{\circ} \mathrm{C}, R_{\mathrm{f}} 0.2$ (50\% AcOEt in hexanes), $[a]_{D}^{25}-45.9$ (c $\left.0.098, \mathrm{MeOH}\right)$; IR (ATR): v 3326 (m, OH), 2912 (m), 1605 (s), 1509 (s), 1053 (vs), 1008 (vs), 839 (vs) cm ${ }^{-1} ;{ }^{1} \mathrm{H}$ NMR (300 MHz, $\left.\left(\mathrm{CD}_{3}\right)_{2} \mathrm{CO}\right): \delta 1.24\left(\mathrm{~d}, 3 \mathrm{H}, J_{\mathrm{Me}, 2}=6.1 \mathrm{~Hz}, \mathrm{Me}\right), 3.65-3.82(\mathrm{~m}, 5 \mathrm{H}, \mathrm{H}-2, \mathrm{H}-3$ or H-4, OMe), 3.93 (“q”, 1H, $J=5.3 \mathrm{~Hz}, \mathrm{H}-3$ or H-4), 4.12 (d, 1H, $J=5.5 \mathrm{~Hz}, \mathrm{OH}), 4.24$ (d, 1H, $J$ $=5.5 \mathrm{~Hz}, \mathrm{OH}), 4.56\left(\mathrm{ddd}, 1 \mathrm{H}, J_{1^{\prime}, 5}=9.2, J_{4,5}=5.1, J=0.6 \mathrm{~Hz}, \mathrm{H}-5\right), 5.56\left(\mathrm{dd}, 1 \mathrm{H}, J_{1^{\prime}, 2^{\prime}}=11.6\right.$, $\left.J_{1^{\prime}, 5}=9.2 \mathrm{~Hz}, \mathrm{H}-1^{\prime}\right), 6.58\left(\mathrm{~d}, 1 \mathrm{H}, J_{1^{\prime}, 2^{\prime}}=11.7 \mathrm{~Hz}, \mathrm{H}-2^{\prime}\right), 6.92(\mathrm{~d}, 2 \mathrm{H}, J=8.8 \mathrm{~Hz}, \mathrm{Ph}), 7.43(\mathrm{~d}, 2 \mathrm{H}$, $J=8.7 \mathrm{~Hz}, \mathrm{Ph}) ;{ }^{13} \mathrm{C} \mathrm{NMR}\left(75 \mathrm{MHz},\left(\mathrm{CD}_{3}\right)_{2} \mathrm{CO}\right): \delta 20.5$ (q, Me), 56.5 (q, OMe), 78.1, 78.6, 80.9, 81.5 (all d, C-2, C-3, C-4, C-5), 115.3 (d, C-5’ C-7’), 130.9 (s, C-3’), 131.5, 132.2, 133.7 (all d, C-1', C-2', C-4', C-8'), 161.0 (s, C-6'). HRMS m/z Calc. for $\mathrm{C}_{14} \mathrm{H}_{18} \mathrm{NaO}_{4}{ }^{+}$: 273.1097, found $273.0960[\mathrm{M}+\mathrm{Na}]^{+}$.

$E$-(2S,3R,4S,5R)-5-(2,4-Dimethoxystyryl)-2-methyltetrahydrofuran-3,4-diol (6e). Yield: 60 $\mathrm{mg}(61 \%) ; R_{\mathrm{f}} 0.2$ (50\% AcOEt in hexanes), $[a]_{D}^{25}+12.4$ (c 0.631, MeOH); IR (ATR): $v 3382(\mathrm{~m}$, $\mathrm{OH}), 2966$ (m), 2920 (m), 1611 (s), 1499 (s), 1154 (vs), 1030 (vs), 763 (s) cm ${ }^{-1}$; ${ }^{1} \mathrm{H}$ NMR (300 $\left.\mathrm{MHz},\left(\mathrm{CD}_{3}\right)_{2} \mathrm{CO}\right): \delta 1.26\left(\mathrm{~d}, 3 \mathrm{H}, J_{\mathrm{Me}, 2}=6.3 \mathrm{~Hz}, \mathrm{Me}\right), 3.63-3.71(\mathrm{~m}, 1 \mathrm{H}), 3.74-3.85(\mathrm{~m}, 8 \mathrm{H}, \mathrm{H}-2$, $\mathrm{H}-3, \mathrm{H}-4,2 \times \mathrm{OMe}), 4.21$ (dt, $\left.1 \mathrm{H}, J_{4,5}=J_{1^{\prime}, 5}=6.2, J_{5,2^{\prime}}=0.9 \mathrm{~Hz}, \mathrm{H}-5\right), 6.15\left(\mathrm{dd}, 1 \mathrm{H}, J_{1^{\prime}, 2^{\prime}}=16.0\right.$, $\left.J_{1^{\prime}, 5}=7.0 \mathrm{~Hz}, \mathrm{H}^{-1}{ }^{\prime}\right), 6.50(\mathrm{dd}, 1 \mathrm{H}, J=8.4, J=2.4 \mathrm{~Hz}, \mathrm{Ph}), 6.54(\mathrm{~d}, 1 \mathrm{H}, J=2.3 \mathrm{~Hz}, \mathrm{Ph}), 6.85(\mathrm{~d}$, $\left.1 \mathrm{H}, J_{1^{\prime}, 2^{\prime}}=16.1 \mathrm{~Hz}, \mathrm{H}-2^{\prime}\right), 7.40(\mathrm{~d}, 1 \mathrm{H}, J=8.4 \mathrm{~Hz}, \mathrm{Ph}) ;{ }^{13} \mathrm{C} \mathrm{NMR}\left(75 \mathrm{MHz},\left(\mathrm{CD}_{3}\right)_{2} \mathrm{CO}\right): \delta 20.5$ (q, Me), 56.6, 56.8 (2 x q, 2 x OMe), 77.9, 78.1, 80.9, 86.5 (all d, C-2, C-3, C-4, C-5), 99.9 (d, C5’), 107.0 (d, C-7’), 120.3 (s, C-3'), 127.4, 128.8, 129.3 (all d, C-1', C-2', C-8’), 159.8, 162.6 (all s, C-4', C-6'). HRMS $m / z$ Calc. for $\mathrm{C}_{15} \mathrm{H}_{20} \mathrm{NaO}_{5}{ }^{+}: 303.1203$, found $303.1262[\mathrm{M}+\mathrm{Na}]^{+}$.

$\boldsymbol{E}$-(2S,3R,4S,5R)-5-(2,5-Dimethoxystyryl)-2-methyltetrahydrofuran-3,4-diol (6f). Yield: 63 $\mathrm{mg}(53 \%) ; R_{\mathrm{f}} 0.2$ (50\% AcOEt in hexanes), $[a]_{D}^{25}+36.0$ (c 0.692, MeOH); IR (ATR): $v 3376$ (m, $\mathrm{OH}$ ), 2928 (m), 1494 (vs), 1219 (vs), 1043 (vs), 1023 (vs), 970 (s) cm ${ }^{-1} ;{ }^{1} \mathrm{H}$ NMR (300 MHz, $\left.\left(\mathrm{CD}_{3}\right)_{2} \mathrm{CO}\right): \delta 1.27$ (d, 3H, $\left.J_{\mathrm{Me}, 2}=6.3 \mathrm{~Hz}, \mathrm{Me}\right), 3.69$ (“t”, $1 \mathrm{H}, J=5.7 \mathrm{~Hz}, \mathrm{H}-3$ or H-4), 3.76, 3.79 ( 2 x s, 6H, 2 x OMe), 3.83 (“qi", $1 \mathrm{H}, J_{\mathrm{Me}, 2}=J_{2,3}=6.1 \mathrm{~Hz}, \mathrm{H}-2$ ), 3.89 (“t”, $1 \mathrm{H}, J=5.7 \mathrm{~Hz}, \mathrm{H}-3$ or $\mathrm{H}-4), 4.25\left(\mathrm{dt}, 1 \mathrm{H}, J_{1^{\prime}, 5}=6.5, J_{4,5}=5.5, J_{5,2^{\prime}}=0.9 \mathrm{~Hz}, \mathrm{H}-5\right), 6.31\left(\mathrm{dd}, 1 \mathrm{H}, J_{1^{\prime}, 2^{\prime}}=16.1, J_{1^{\prime}, 5}=6.7\right.$ $\left.\mathrm{Hz}, \mathrm{H}-1^{\prime}\right), 6.80\left(\mathrm{dd}, 1 \mathrm{H}, J_{5^{\prime} 6^{\prime}}=8.9, J_{6^{\prime} 8^{\prime}}=3.0 \mathrm{~Hz}, \mathrm{C}-6^{\prime}\right), 6.91\left(\mathrm{~d}, 1 \mathrm{H}, J_{5^{\prime} 6^{\prime}}=8.9 \mathrm{~Hz}, \mathrm{C}-5^{\prime}\right), 6.94$ $\left(\mathrm{dd}, 1 \mathrm{H}, J_{1^{\prime}, 2^{\prime}}=15.8, J_{5,2^{\prime}}=0.9 \mathrm{~Hz}, \mathrm{H}-2^{\prime}\right), 7.08\left(\mathrm{~d}, 1 \mathrm{H}, J_{6^{\prime}} 8^{\prime}=3.0 \mathrm{~Hz}, \mathrm{C}-8^{\prime}\right) ;{ }^{13} \mathrm{C} \mathrm{NMR}(75 \mathrm{MHz}$, $\left.\left(\mathrm{CD}_{3}\right)_{2} \mathrm{CO}\right): \delta 20.5$ (q, Me), 56.8, $57.4(2 \mathrm{x} \mathrm{q}, 2$ x OMe), 77.4, 78.1, 81.0, 86.5 (all d, C-2, C-3, C4, C-5), 113.5, 114.2, 115.6 (all d, C-5', C-6’, C-8’), 127.2 (d, C-1' or C-2’), 128.2 (s, C-3’), 131.5 (d, C-1' or C-2'), 153.0, 155.6 (all s, C-4', C-7'). HRMS m/z Calc. for $\mathrm{C}_{15} \mathrm{H}_{20} \mathrm{NaO}_{5}{ }^{+}$: 303.1203, found $303.1078[\mathrm{M}+\mathrm{Na}]^{+}$. 
$E$-(2S,3R,4S,5R)-5-(2-(Trifluoromethyl)styryl)-2-methyltetrahydrofuran-3,4-diol

$(6 \mathrm{~g})$.

Yield: $50 \mathrm{mg}(41 \%) ; R_{\mathrm{f}} 0.2\left(50 \%\right.$ AcOEt in hexanes), $[a]_{D}^{25}+51.6(c 0.486, \mathrm{MeOH}) ; \mathrm{IR}(\mathrm{ATR}): v$ 3376 (w, OH), 2931 (w), 1715 (m), 1312 (vs), 1104 (vs), 1034 (vs), 764 (vs) cm ${ }^{-1}$; ${ }^{1} \mathrm{H}$ NMR (300 $\mathrm{MHz},\left(\mathrm{CD}_{3}\right)_{2} \mathrm{CO}$ ): $\delta 1.28$ (d, 3H, $J_{\mathrm{Me}, 2}=6.3 \mathrm{~Hz}, \mathrm{Me}$ ), 3.70 (“t”, $1 \mathrm{H}, J=5.7 \mathrm{~Hz}, \mathrm{H}-3$ or H-4), 3.90 ("qi", $\left.1 \mathrm{H}, J_{\mathrm{Me}, 2}=J_{2,3}=6.2 \mathrm{~Hz}, \mathrm{H}-2\right) 3.95$ ("t", $1 \mathrm{H}, J=5.3 \mathrm{~Hz}, \mathrm{H}-3$ or H-4), 4.35 ("dt", $1 \mathrm{H}, J_{1^{\prime}, 5}=$ $\left.J_{4,5}=5.3, J_{5,2^{\prime}}=1.3 \mathrm{~Hz}, \mathrm{H}-5\right), 6.43\left(\mathrm{dd}, 1 \mathrm{H}, J_{1^{\prime}, 2^{\prime}}=15.7, J_{5,1^{\prime}}=5.7 \mathrm{~Hz}, \mathrm{H}-1^{\prime}\right), 7.06\left(\mathrm{dd}, 1 \mathrm{H}, J_{1^{\prime}, 2^{\prime}}=\right.$ $\left.15.7, J_{5,2^{\prime}}=1.7 \mathrm{~Hz}, \mathrm{H}-2^{\prime}\right), 7.45$ (t, $\left.1 \mathrm{H}, J=7.6 \mathrm{~Hz}, \mathrm{Ph}\right), 7.62$ (t, 1H, $\left.J=7.6 \mathrm{~Hz}, \mathrm{Ph}\right), 7.70$ (d, 1H, $J$ $=7.9 \mathrm{~Hz}, \mathrm{Ph}), 7.81(\mathrm{~d}, 1 \mathrm{H}, J=7.9 \mathrm{~Hz}, \mathrm{Ph}) ;{ }^{13} \mathrm{C} \mathrm{NMR}\left(75 \mathrm{MHz},\left(\mathrm{CD}_{3}\right)_{2} \mathrm{CO}\right): \delta 20.4,(\mathrm{q}, \mathrm{Me})$, 77.5, 78.1, 81.0, 85.6 (all d, C-2, C-3, C-4, C-5), 126.5 (q, $\left.J_{\mathrm{C}, \mathrm{F}}=272.0 \mathrm{~Hz}, \underline{\mathrm{CF}}_{3}\right), 127.3$ (q, $J_{\mathrm{C}, \mathrm{F}}=$ $2.1 \mathrm{~Hz}), 127.5\left(\mathrm{q}, J_{\mathrm{C}, \mathrm{F}}=5.8 \mathrm{~Hz}\right), 128.5\left(\mathrm{q}, J_{\mathrm{C}, \mathrm{F}}=29.5 \mathrm{~Hz}, \mathrm{C}_{-} 4^{\prime}\right), 129.3,129.4$ (all d), $134.2\left(\mathrm{q}, J_{\mathrm{C}, \mathrm{F}}\right.$ $=1.0 \mathrm{~Hz}), 135.9$ (d) $137.8\left(\mathrm{q}, J_{\mathrm{C}, \mathrm{F}}=1.6 \mathrm{~Hz}\right)$; HRMS $\mathrm{m} / z$ Calc. for $\mathrm{C}_{14} \mathrm{H}_{15} \mathrm{~F}_{3} \mathrm{NaO}_{3}{ }^{+}: 311.0866$, found $311.0709[\mathrm{M}+\mathrm{Na}]^{+}$.

E-(2S,3R,4S,5R)-5-(3-(Trifluoromethyl)styryl)-2-methyltetrahydrofuran-3,4-diol

(6h). Yield: $46 \mathrm{mg}$ (37\%); $R_{\mathrm{f}} 0.2$ (50\% AcOEt in hexanes), $[a]_{D}^{25}+35.6$ (c 0.438, MeOH); IR (ATR): $v$ 3392 (w, OH), 2931 (w), 1705 (m), 1330 (vs), 1119 (vs), 1070 (vs), 978 (s) cm ${ }^{-1} ;{ }^{1} \mathrm{H}$ NMR (300 $\mathrm{MHz},\left(\mathrm{CDCl}_{3}\right): \delta 1.35$ (d, 3H, $\left.J_{\mathrm{Me}, 2}=6.4 \mathrm{~Hz}, \mathrm{Me}\right), 3.24$ (bs, 2H, 2 x OH) 3.78 (“t”, $1 \mathrm{H}, J=5.6$ Hz, H-3 or H-4), 3.89-3.99 (m, 2H, H-2, H-3 or H-4) 4.33 (" $\mathrm{t}$ ", $1 \mathrm{H}, J_{1^{\prime}, 5}=6.2, J_{4,5}=6.0 \mathrm{~Hz}, \mathrm{H}-$ 5), ), $6.29\left(\mathrm{dd}, 1 \mathrm{H}, J_{1^{\prime}, 2^{\prime}}=15.9, J_{1^{\prime}, 5}=6.6 \mathrm{~Hz}, \mathrm{H}-1^{\prime}\right), 6.72\left(\mathrm{~d}, 1 \mathrm{H}, J_{1^{\prime}, 2^{\prime}}=15.9 \mathrm{~Hz}, \mathrm{H}-2^{\prime}\right), 7.34-7.54$ $(\mathrm{m}, 3 \mathrm{H}, \mathrm{Ph}), 7.62$ (s, 1H, Ph); ${ }^{13} \mathrm{C}$ NMR (75 MHz, $\left(\mathrm{CDCl}_{3}\right): \delta 19.0$ (q, Me), 75.5, 76.2, 79.8, 83.8 (all d, C-2, C-3, C-4, C-5), 123.1 (q, $J_{\mathrm{C}, \mathrm{F}}=3.8 \mathrm{~Hz}, \mathrm{C}-4^{\prime}$ or C-6'), 124.0 (q, $J_{\mathrm{C}, \mathrm{F}}=272.4 \mathrm{~Hz}, \underline{\mathrm{CF}}_{3}$ ), 124.4 (q, $J_{\mathrm{C}, \mathrm{F}}=3.8 \mathrm{~Hz}, \mathrm{C}-4^{\prime}$ or C-6’), 129.0, 129.3, 130.9 (all d, C-1', C-2’', C-8’), 129.7 (q, $J_{\mathrm{C}, \mathrm{F}}$ $\left.=1.1 \mathrm{~Hz}, \mathrm{C}-7^{\prime}\right), 130.9\left(\mathrm{q}, J_{\mathrm{C}, \mathrm{F}}=32.2 \mathrm{~Hz}, \mathrm{C}-5^{\prime}\right), 137.0\left(\mathrm{~s}, \mathrm{C}-3^{\prime}\right)$. HRMS m/z Calc. for $\mathrm{C}_{14} \mathrm{H}_{15} \mathrm{~F}_{3} \mathrm{NaO}_{3}^{+}: 311.0866$, found $311.0810[\mathrm{M}+\mathrm{Na}]^{+}$.

Z-(2S,3R,4S,5R)-5-(3-(Trifluoromethyl)styryl)-2-methyltetrahydrofuran-3,4-diol

(7h).

Yield: $31 \mathrm{mg}$ (25\%); m.p. 82-83 ${ }^{\circ} \mathrm{C}, R_{\mathrm{f}} 0.3$ (50\% AcOEt in hexanes), $[a]_{D}^{25}-32.8$ (c 0.345, $\mathrm{MeOH}$ ); IR (ATR): v 3371 (m, OH), 2929 (w), 1486 (w), 1443 (m), 1327 (vs), 1118 (vs), 1074 (vs), 806 (s) cm ${ }^{-1} ;{ }^{1} \mathrm{H}$ NMR $\left(300 \mathrm{MHz},\left(\mathrm{CDCl}_{3}\right): \delta 1.35\right.$ (d, 3H, $\left.J_{\mathrm{Me}, 2}=6.4 \mathrm{~Hz}, \mathrm{Me}\right), 2.92$ (bs, 2H, 2 x OH) 3.74 ("t", $1 \mathrm{H}, J=5.8 \mathrm{~Hz}, \mathrm{H}-3$ or H-4), 3.81 ("qii", $1 \mathrm{H}, J_{\mathrm{Me}, 2}=J_{2,3}=6.1 \mathrm{~Hz}, \mathrm{H}-2$ ), 3.96 (“'t”, $1 \mathrm{H}, J=6.0 \mathrm{~Hz}, \mathrm{H}-3$ or H-4) 4.46 (dd, $\left.1 \mathrm{H}, J_{1^{\prime}, 5}=9.3, J_{4,5}=5.9 \mathrm{~Hz}, \mathrm{H}-5\right), 5.73$ (dd, $1 \mathrm{H}, J_{1^{\prime}, 2^{\prime}}$ $\left.=11.6, J_{1^{\prime}, 5}=9.3 \mathrm{~Hz}, \mathrm{H}-1^{\prime}\right), 6.75\left(\mathrm{~d}, 1 \mathrm{H}, J_{1^{\prime}, 2^{\prime}}=11.6 \mathrm{~Hz}, \mathrm{H}-2^{\prime}\right), 7.40-7.70(\mathrm{~m}, 4 \mathrm{H}, \mathrm{Ph}) ;{ }^{13} \mathrm{C} \mathrm{NMR}$ (75 MHz, $\left(\mathrm{CDCl}_{3}\right): \delta 18.9$ (q, Me), 75.8, 76.3, 79.0, 79.7 (all d, C-2, C-3, C-4, C-5), 124.0 (q, $\left.J_{\mathrm{C}, \mathrm{F}}=272.3 \mathrm{~Hz}, \underline{\mathrm{CF}}_{3}\right), 124.2\left(\mathrm{q}, J_{\mathrm{C}, \mathrm{F}}=3.8 \mathrm{~Hz}, \mathrm{C}^{-} 4^{\prime}\right.$ or $\left.\mathrm{C}^{\prime} 6^{\prime}\right), 125.7\left(\mathrm{q}, J_{\mathrm{C}, \mathrm{F}}=3.8 \mathrm{~Hz}, \mathrm{C}^{\prime} 4^{\prime}\right.$ or $\mathrm{C}^{\prime}$ $\left.6^{\prime}\right), 130.6$ (q, $\left.J_{\mathrm{C}, \mathrm{F}}=32.2 \mathrm{~Hz}, \mathrm{C}^{\prime} 5^{\prime}\right) 132.1$ (q, $J_{\mathrm{C}, \mathrm{F}}=1.1 \mathrm{~Hz}, \mathrm{C}-7^{\prime}$ ), 128.7, 131.1, 132.9 (all d, C-1', C-2', C-8'), 136.6 (s, C-3'). HRMS $m / z$ Calc. for $\mathrm{C}_{14} \mathrm{H}_{15} \mathrm{~F}_{3} \mathrm{NaO}_{3}{ }^{+}$: 311.0866, found 311.0699 $[\mathrm{M}+\mathrm{Na}]^{+}$.

$\boldsymbol{E}$-(2S,3R,4S,5R)-5-(4-Bromostyryl)-2-methyltetrahydrofuran-3,4-diol (6i). Yield: $71 \mathrm{mg}$ (56\%, white solid); m.p. 139-140 ${ }^{\circ} \mathrm{C}, R_{\mathrm{f}} 0.2$ (50\% AcOEt in hexanes), $[a]_{D}^{25}+49.9$ (c 0.593, $\mathrm{MeOH}$ ); IR (ATR): v 3348 (m, OH), 3287 (m, OH), 2918 (m), 1487 (m), 1125 (s), 1054 (vs), 971 (vs), 841 (vs) cm ${ }^{-1}$; ${ }^{1} \mathrm{H}$ NMR (300 MHz, $\left.\left(\mathrm{CD}_{3}\right)_{2} \mathrm{CO}\right): \delta 1.26\left(\mathrm{~d}, 3 \mathrm{H}, J_{\mathrm{Me}, 2}=6.3 \mathrm{~Hz}, \mathrm{Me}\right), 3.70$ (“t”, $1 \mathrm{H}, J=5.7 \mathrm{~Hz}, \mathrm{H}-3$ or H-4), 3.84 ("qii", $1 \mathrm{H}, J_{\mathrm{Me}, 2}=J_{2,3}=6.1 \mathrm{~Hz}, \mathrm{H}-2$ ) 3.89 ("t", $1 \mathrm{H}, J=5.7$ 
Hz, H-3 or H-4), 4.25(“bt”, $\left.1 \mathrm{H}, J_{1^{\prime}, 5}=J_{4,5}=6.4 \mathrm{~Hz}, \mathrm{H}-5\right), 6.37$ (dd, $1 \mathrm{H}, J_{1^{\prime}, 2^{\prime}}=15.9, J_{1^{\prime}, 5}=6.4 \mathrm{~Hz}$, $\left.\mathrm{H}^{-1}{ }^{\prime}\right), 6.64\left(\mathrm{~d}, 1 \mathrm{H}, J_{1^{\prime}, 2^{\prime}}=16.0 \mathrm{~Hz}, \mathrm{H}-2^{\prime}\right), 7.41(\mathrm{~d}, 2 \mathrm{H}, J=8.5 \mathrm{~Hz}, \mathrm{Ph}), 7.50(\mathrm{~d}, 2 \mathrm{H}, J=8.6 \mathrm{~Hz}$, $\mathrm{Ph}) ;{ }^{13} \mathrm{C}$ NMR $\left(75 \mathrm{MHz},\left(\mathrm{CD}_{3}\right)_{2} \mathrm{CO}\right): \delta 20.5$ (q, Me), 77.4, 78.1, 81.2, 85.9 (all d, C-2, C-3, C-4, C-5), 122.5 (s, C-6’), 130.1 (d, C-4’, C-8’), 131.1, 132.2 (all d, C-1', C-2’), 133.4 (d, C-5’, C-7’'), 138.1 (s, C-3'). HRMS m/z Calc. for $\mathrm{C}_{13} \mathrm{H}_{15} \mathrm{BrNaO}_{3}{ }^{+}: 321.0097$, found 321.0057 [M+Na] ${ }^{+}$.

Z-(2S,3R,4S,5R)-5-(4-Bromostyryl)-2-methyltetrahydrofuran-3,4-diol (7i). Yield: $45 \mathrm{mg}$ (35\%, white solid); m.p. 100-102 ${ }^{\circ} \mathrm{C}, R_{\mathrm{f}} 0.3$ (50\% AcOEt in hexanes), $[a]_{D}^{25}-52.9$ (c 0.413,

$\mathrm{MeOH}$ ); IR (ATR): v 3375 (m, OH), 2917 (m), 1585 (w), 1486 (s), 1070 (vs), 1006 (vs), 836 (vs), 717 (s) cm ${ }^{-1} ;{ }^{1} \mathrm{H}$ NMR (300 MHz, $\left.\left(\mathrm{CD}_{3}\right)_{2} \mathrm{CO}\right): \delta 1.24\left(\mathrm{~d}, 3 \mathrm{H}, J_{\mathrm{Me}, 2}=6.1 \mathrm{~Hz}, \mathrm{Me}\right), 3.71$ ("t't", $\left.1 \mathrm{H}, J_{2,3}=J_{3,4}=5.7 \mathrm{~Hz}, \mathrm{H}-3\right), 3.79\left(\mathrm{dq}, 1 \mathrm{H}, J_{\mathrm{Me}, 2}=6.1, J_{2,3}=5.7 \mathrm{~Hz}, \mathrm{H}-2\right), 3.95\left(\mathrm{dd}, 1 \mathrm{H}, J_{3,4}=\right.$ $\left.5.7, J_{4,5}=5.4 \mathrm{~Hz}, \mathrm{H}-4\right), 4.50\left(\mathrm{ddd}, 1 \mathrm{H}, J_{1^{\prime}, 5}=9.3, J_{4,5}=5.4, J_{2^{\prime}, 5}=0.6 \mathrm{~Hz}, \mathrm{H}-5\right), 5.72(\mathrm{dd}, 1 \mathrm{H}$, $\left.J_{1^{\prime}, 2^{\prime}}=11.7, J_{1^{\prime}, 5}=9.3 \mathrm{~Hz}, \mathrm{H}-1^{\prime}\right), 6.63\left(\mathrm{bd}, 1 \mathrm{H}, J_{1^{\prime}, 2^{\prime}}=11.7 \mathrm{~Hz}, \mathrm{H}-2^{\prime}\right), 7.43$ (d, 2H, $J=8.5 \mathrm{~Hz}$, $\mathrm{Ph}), 7.53(\mathrm{~d}, 2 \mathrm{H}, J=8.5 \mathrm{~Hz}, \mathrm{Ph}) ;{ }^{13} \mathrm{C} \mathrm{NMR}\left(75 \mathrm{MHz},\left(\mathrm{CD}_{3}\right)_{2} \mathrm{CO}\right): \delta 20.5$ (q, Me), 78.0, 78.4, 81.0, 81.1 (all d, C-2, C-3, C-4, C-5), 122.7 (s, C-6'), 132.8, 132.9, 133.0, 134.2 (all d, C-1', C2', C-4', C-5', C-7', C-8' ), 137.5 (s, C-3'). HRMS m/z Calc. for $\mathrm{C}_{13} \mathrm{H}_{15} \mathrm{BrNaO}_{3}^{+}$: 321.0097 , found $321.0095[\mathrm{M}+\mathrm{Na}]^{+}$.

$\boldsymbol{E}$-(2S,3R,4S,5R)-5-(2-Fluorostyryl)-2-methyltetrahydrofuran-3,4-diol (6j). Yield: $44 \mathrm{mg}$ (35\%, white solid); m.p. 47-49 ${ }^{\circ} \mathrm{C}, R_{\mathrm{f}} 0.3$ (50\% AcOEt in hexanes), $[a]_{D}^{25}+44.9$ (c 0.274, MeOH); IR (ATR): v 3327 (m, OH), 2980 (m), 2921(m), 1658 (w), 1487 (s), 1453 (s), 1231 (s), 1055 (vs), 967 (vs), 764 (vs) cm ${ }^{-1} ;{ }^{1} \mathrm{H}$ NMR (300 MHz, $\left.\left(\mathrm{CD}_{3}\right)_{2} \mathrm{CO}\right): \delta 1.28$ (d, 3H, $J_{\mathrm{Me}, 2}=6.3 \mathrm{~Hz}, \mathrm{Me}$ ), 3.70 ("'t", $1 \mathrm{H}, J=5.6 \mathrm{~Hz}, \mathrm{H}-3$ or H-4), 3.86 (“qii", $1 \mathrm{H}, J_{\mathrm{Me}, 2}=J_{2,3}=6.2 \mathrm{~Hz}, \mathrm{H}-2$ ), 3.91 (“t”, $1 \mathrm{H}, J$ $=5.7 \mathrm{~Hz}, \mathrm{H}-3$ or H-4) 4.29 (bt, $\left.1 \mathrm{H}, J_{1^{\prime}, 5}=J_{4,5}=5.8 \mathrm{~Hz}, \mathrm{H}-5\right), 6.45$ (dd, 1H, $J_{1^{\prime}, 2^{\prime}}=16.1, J_{1^{\prime}, 5}=6.2$ $\left.\mathrm{Hz}, \mathrm{H}-1^{\prime}\right), 6.81$ (bd, 1H, $\left.J_{1^{\prime}, 2^{\prime}}=16.1 \mathrm{~Hz}, \mathrm{H}-2^{\prime}\right), 7.04-7.20$ (m, 2H, Ph), 7.24-7.34 (m, 1H, Ph), $7.61(\mathrm{dt}, 1 \mathrm{H}, J=7.8, J=1.6 \mathrm{~Hz}, \mathrm{Ph}) ;{ }^{13} \mathrm{C} \mathrm{NMR}\left(75 \mathrm{MHz},\left(\mathrm{CD}_{3}\right)_{2} \mathrm{CO}\right): \delta 20.5$ (q, Me), 77.4, 78.1, 81.2, 86.0 (all d, C-2, C-3, C-4, C-5), 117.4 (d, $\left.J_{\mathrm{C}, \mathrm{F}}=22.2 \mathrm{~Hz}, \mathrm{C}-5^{\prime}\right), 124.2$ (d, $J_{\mathrm{C}, \mathrm{F}}=3.9 \mathrm{~Hz}, \mathrm{C}-$ $\left.7^{\prime}\right), 126.3\left(\mathrm{~d}, J_{\mathrm{C}, \mathrm{F}}=3.5 \mathrm{~Hz}, \mathrm{C}-1^{\prime}\right), 126.4\left(\mathrm{~d}, J_{\mathrm{C}, \mathrm{F}}=11.2 \mathrm{~Hz}, \mathrm{C}-3^{\prime}\right), 129.4$ (d, $\left.J_{\mathrm{C}, \mathrm{F}}=3.7 \mathrm{~Hz}, \mathrm{C}^{\prime} 8^{\prime}\right)$, $130.9\left(\mathrm{~d}, J_{\mathrm{C}, \mathrm{F}}=8.5 \mathrm{~Hz}, \mathrm{C}^{-6} 6^{\prime}\right), 134.0\left(\mathrm{~d}, J_{\mathrm{C}, \mathrm{F}}=4.6 \mathrm{~Hz}, \mathrm{C}-2^{\prime}\right), 162.0\left(\mathrm{~d}, J_{\mathrm{C}, \mathrm{F}}=247.3 \mathrm{~Hz}, \mathrm{C}^{\prime} 4^{\prime}\right)$ HRMS $m / z$ Calc. for $\mathrm{C}_{13} \mathrm{H}_{16} \mathrm{FO}_{3}{ }^{+}: 239.1078$, found $239.1034[\mathrm{M}+\mathrm{H}]^{+}$.

$\boldsymbol{E}$-(2S,3R,4S,5R)-5-(4-Fluorostyryl)-2-methyltetrahydrofuran-3,4-diol (6k). Yield: $42 \mathrm{mg}$ (30\%, white solid); m.p. $116-119^{\circ} \mathrm{C}, R_{\mathrm{f}} 0.2$ (50\% AcOEt in hexanes), $[a]_{D}^{25}+47.7$ (c 0.239, $\mathrm{MeOH}$ ); IR (ATR): v 3288 (m, OH), 2924 (m), 1657 (w), 1603 (s), 1508 (vs), 1230 (vs), 1055 (vs), 970 (vs), 832 (vs) cm ${ }^{-1} ;{ }^{1} \mathrm{H}$ NMR (300 MHz, $\left.\left(\mathrm{CD}_{3}\right)_{2} \mathrm{CO}\right): \delta 1.26$ (d, 3H, $J_{\mathrm{Me}, 2}=6.3 \mathrm{~Hz}, \mathrm{Me}$ ), 3.67 (“t”, $1 \mathrm{H}, J=5.7 \mathrm{~Hz}, \mathrm{H}-3$ or H-4), 3.83 (“qii", $1 \mathrm{H}, J_{\mathrm{Me}, 2}=J_{2,3}=6.0 \mathrm{~Hz}, \mathrm{H}-2$ ), 3.89 (“"t”, $1 \mathrm{H}, J$ $=5.6 \mathrm{~Hz}, \mathrm{H}-3$ or H-4) $4.20\left(\mathrm{dt}, 1 \mathrm{H}, J_{1^{\prime}, 5}=J_{4,5}=6.0, J_{2^{\prime}, 5}=0.9 \mathrm{~Hz}, \mathrm{H}-5\right), 6.27\left(\mathrm{dd}, 1 \mathrm{H}, J_{1^{\prime}, 2^{\prime}}=\right.$ $\left.15.9, J_{1^{\prime}, 5}=6.5 \mathrm{~Hz}, \mathrm{~Hz}, \mathrm{H}-1^{\prime}\right), 6.66\left(\mathrm{bd}, 1 \mathrm{H}, J_{1^{\prime}, 2^{\prime}}=15.9 \mathrm{~Hz}, \mathrm{H}-2^{\prime}\right), 7.05-7.14$ (m, 2H, Ph), 7.46$7.53(\mathrm{~m}, 2 \mathrm{H}, \mathrm{Ph}) ;{ }^{13} \mathrm{C}$ NMR (75 MHz, $\left.\left(\mathrm{CD}_{3}\right)_{2} \mathrm{CO}\right): \delta 20.5$ (q, Me), 77.4, 78.1, 81.1, 86.0 (all d, C-2, C-3, C-4, C-5), 117.1 (d, $\left.J_{\mathrm{C}, \mathrm{F}}=21.7 \mathrm{~Hz}, \mathrm{C}^{-5^{\prime}}, \mathrm{C}^{-} 7^{\prime}\right), 130.0$ (d, $\left.J_{\mathrm{C}, \mathrm{F}}=8.1 \mathrm{~Hz}, \mathrm{C}^{\prime} 4^{\prime}, \mathrm{C}^{\prime} 8^{\prime}\right)$, $131.0\left(\mathrm{~d}, J_{\mathrm{C}, \mathrm{F}}=2.2 \mathrm{~Hz}, \mathrm{C}-2^{\prime}\right), 131.2\left(\mathrm{~d}, \mathrm{C}-1^{\prime}\right), 135.3\left(\mathrm{~s}, J_{\mathrm{C}, \mathrm{F}}=3.2 \mathrm{~Hz}, \mathrm{C}-3^{\prime}\right), 164.0\left(\mathrm{~d}, J_{\mathrm{C}, \mathrm{F}}=\right.$ $\left.244.7 \mathrm{~Hz}, \mathrm{C}-6^{\prime}\right)$. HRMS $\mathrm{m} / z$ Calc. for $\mathrm{C}_{13} \mathrm{H}_{15} \mathrm{FNaO}_{3}{ }^{+}: 261.0897$, found 261.0867 [M+Na] ${ }^{+}$. 
Z-(2S,3R,4S,5R)-5-(4-Fluorostyryl)-2-methyltetrahydrofuran-3,4-diol (7k). Yield: $11 \mathrm{mg}$ (8\%, white solid); m.p. $70-73{ }^{\circ} \mathrm{C}, R_{\mathrm{f}} 0.3$ (50\% AcOEt in hexanes), $[a]_{b}^{25}-34.9$ (c 0.126, MeOH); IR (ATR): v 3458 (m, OH), 3323 (m, OH), 2978 (m), 2903 (m), 1602 (m), 1505 (s), 1220 (vs), 1086 (vs), 982 (vs), 848 (vs), $\mathrm{cm}^{-1}$; ${ }^{1} \mathrm{H}$ NMR (300 MHz, $\left.\left(\mathrm{CD}_{3}\right)_{2} \mathrm{CO}\right): \delta 1.24$ (d, 3H, $J_{\mathrm{Me}, 2}=6.2$ $\mathrm{Hz}, \mathrm{Me}$ ), 3.71 (“t”, $1 \mathrm{H}, J=5.8 \mathrm{~Hz}, \mathrm{H}-3$ or H-4), 3.77 (“qi", $1 \mathrm{H}, J_{\mathrm{Me}, 2}=J_{2,3}=6.1 \mathrm{~Hz}, \mathrm{H}-2$ ), 3.95 (“t”, $1 \mathrm{H}, J=5.4 \mathrm{~Hz}, \mathrm{H}-3$ or H-4) $4.50\left(\mathrm{dt}, 1 \mathrm{H}, J_{1^{\prime}, 5}=9.3, J_{4,5}=5.4 \mathrm{~Hz}, \mathrm{H}-5\right), 5.67$ (dd, 1H, $J_{1^{\prime}, 2^{\prime}}=$ $\left.11.7, J_{1^{\prime}, 5}=9.3 \mathrm{~Hz}, \mathrm{H}-1^{\prime}\right), 6.65\left(\mathrm{~d}, 1 \mathrm{H}, J_{1^{\prime}, 2^{\prime}}=11.7 \mathrm{~Hz}, \mathrm{H}-2^{\prime}\right), 7.08-7.16(\mathrm{~m}, 2 \mathrm{H}, \mathrm{Ph}), 7.40-7.55$ $(\mathrm{m}, 2 \mathrm{H}, \mathrm{Ph}) ;{ }^{13} \mathrm{C}$ NMR $\left(75 \mathrm{MHz},\left(\mathrm{CD}_{3}\right)_{2} \mathrm{CO}\right): \delta 20.5$ (q, Me), 78.0, 78.4, 81.0, 81.1 (all d, C-2, C-3, C-4, C-5), 116.7 (d, $J_{\mathrm{C}, \mathrm{F}}=21.5 \mathrm{~Hz}, \mathrm{C}^{\prime} 5^{\prime}, \mathrm{C}^{\prime} 7^{\prime}$ ), 132.8 (d, $\left.J_{\mathrm{C}, \mathrm{F}}=8.0 \mathrm{~Hz}, \mathrm{C}-4^{\prime}, \mathrm{C}-8^{\prime}\right), 133.0$ $\left(\mathrm{d}, \mathrm{C}-1^{\prime}\right), 133.3\left(\mathrm{~d}, J_{\mathrm{C}, \mathrm{F}}=1.2 \mathrm{~Hz}, \mathrm{C}-2^{\prime}\right), 134.7$ (s, $\left.J_{\mathrm{C}, \mathrm{F}}=3.3 \mathrm{~Hz}, \mathrm{C}-3^{\prime}\right) 163.9$ (s, $J_{\mathrm{C}, \mathrm{F}}=244.8 \mathrm{~Hz}$, C-6'). HRMS $m / z$ Calc. for $\mathrm{C}_{13} \mathrm{H}_{15} \mathrm{FNaO}_{3}{ }^{+}: 261.0897$, found $261.0813[\mathrm{M}+\mathrm{Na}]^{+}$.

\section{Cytotoxic MTT assay $^{21,22}$}

1. All cells were purchased from the American Tissue Culture Collection (ATCC), unless otherwise indicated: the CCRF-CEM line are highly chemosensitive T-lymphoblastic leukemia cells, K562 cells were derived from patient with acute myeloid leukemia with bcr-abl translocation, A549 line is lung adenocarcinoma, HCT116 is colorectal tumor cell line and its p53 gene knock-down counterpart (HCT116p53-/-, Horizon Discovery, UK) is a model of human cancers with p53 mutation frequently associated with poor prognosis. The daunorubicin resistant subline of CCRF-CEM cells (CEM-DNR bulk) and paclitaxel resistant subline K562tax were selected in our laboratory by the cultivation of maternal cell lines in increasing concentrations of daunorubicine or paclitaxel, respectively. ${ }^{22}$ The CEM-DNR bulk cells overexpress MRP-1 protein, while K562-tax cells overexpress P-glycoprotein, both proteins belong to family of $\mathrm{ABC}$ transporters and are involved in primary and/or acquired multidrug resistance phenomenon. ${ }^{22}$ The cells were maintained in Nunc/Corning $80 \mathrm{~cm}^{2}$ plastic tissue culture flasks and cultured in cell culture medium (DMEM/RPMI 1640 with $5 \mathrm{~g} / \mathrm{L}$ glucose, 2 $\mathrm{mM}$ glutamine, $100 \mathrm{U} / \mathrm{mL}$ penicillin, $100 \mu \mathrm{g} / \mathrm{mL}$ streptomycin, $10 \%$ fetal calf serum, and $\mathrm{NaHCO}_{3}$ ).

2. Cell suspensions were prepared and diluted according to the particular cell type and the expected target cell density (2 500-30 000 cells/well based on cell growth characteristics). Cells were added by pipette $(80 \mu \mathrm{L})$ into 96 -well microtiter plates. Inoculates were allowed a preincubation period of $24 \mathrm{~h}$ at $37{ }^{\circ} \mathrm{C}$ and $5 \% \mathrm{CO}_{2}$ for stabilisation. Four-fold dilutions, in $20-\mu \mathrm{L}$ aliquots, of the intended test concentration were added to the microtiter plate wells at time zero. All test compound concentrations were examined in duplicate. Incubation of the cells with the test compounds lasted for $72 \mathrm{~h}$ at $37{ }^{\circ} \mathrm{C}$, in a $5 \% \mathrm{CO}_{2}$ atmosphere at $100 \%$ humidity. At the end of the incubation period, the cells were assayed using MTT. Aliquots $(10 \mu \mathrm{L})$ of the MTT stock solution were pipetted into each well and incubated for a further 1-4 h. After this incubation period the formazan produced was dissolved by the addition of $100 \mu \mathrm{L} /$ well of $10 \%$ aq SDS (pH $=5.5$ ), followed by a further incubation at $37{ }^{\circ} \mathrm{C}$ overnight. The optical density (OD) was measured at $540 \mathrm{~nm}$ with a Labsystem iEMS Reader MF. Tumour cell survival (TCS) was 
calculated using the following equation: $\mathrm{TCS}=\left(\mathrm{OD}_{\text {drug-exposed well }} /\right.$ mean $\left.\mathrm{OD}_{\text {control wells }}\right) \times 100 \%$. The $\mathrm{TCS}_{50}$ value, the drug concentration lethal to $50 \%$ of the tumour cells, was calculated from appropriate dose-response curves.

\section{Acknowledgements}

Tests on NCI60 were performed at the Developmental Therapeutics Program, Division of Cancer Treatment and Diagnosis, National Cancer Institute (Bethesda, USA).

This work was supported by Slovak Grant Agencies (VEGA, Slovak Academy of Sciences and Ministry of Education, Bratislava, project No. 1/0236/09, APVV, Bratislava, project No. APVT0203-10 and ASFEU, Bratislava, (26240120001, 26240120025), Ministry of Schools, Youth and Education of the Czech Republic (LC07107) and Grant Agency of the Czech Republic (305/09/1216 and 301/09/P433). The infrastructural part of this project (Institute of Molecular and Translational Medicine) was supported from the Operational Program Research and Development for Innovations (project CZ.1.05/2.1.00/01.0030).

\section{References}

1. (a) Fenical, W.; Jensen, P. R. In Marine Biotechnology, Attaway, D. H.; Zaborsky, O. K. Eds.; Plenum Press: New York, 1993, Vol. 1, p 419. (b) Dong, Y.; Shi, Q.; Pai, H.-C.; Peng, C.-Y.; Pan, S.-L.; Teng, C.-M.; Nakagawa-Goto, K.; Yu, D.; Liu, Y.-N.; Wu, P.-C.; Bastow, K.-F.; Morris-Natschke, S. L.; Brossi, A.; Lang, J.-Y.; Hsu, J. L.; Hung, M.-C.; Lee, E.-Y.; Lee, K.-H. J. Med. Chem. 2010, 53, 2299. (c) Faulkner, D. J. Nat. Prod. Rep. 2000, 17, 7.

2. Malmstrøm, J.; Christophersen, C.; Barrero, A. F.; Oltra, J. E.; Justicia, J.; Rosales, A. J. Nat. Prod. 2002, 65, 364.

3. Mayer, A. M. S.; Gustafson, K. R. Eur. J. Cancer. 2004, 40, 2676.

4. Clemens, R. T.; Jennings, M. P. Chem. Commun. 2006, 2720.

5. McAllister, G. D.; Robinson, J. E.; Taylor, R. J. K. Tetrahedron 2007, 63, 12123.

6. (a) Kumar, V.; Shaw, A. K. J. Org. Chem. 2008, 73, 7526. (b) Ghosal, P.; Sharma, D.; Kumar, B.; Meena, S.; Sinha, S.; Shaw, A. K. Org \& Biomol. Chem. 2011, 9, 7372.

7. (a) Palík, M.; Karlubíková, O.; Lásiková, A.; Kožíšek, J.; Gracza, T. Eur. J. Org. Chem. 2009, 709. (b) Palík, M.; Karlubíková, O.; Lackovičová, D.; Lásiková, A.; Gracza, T. Tetrahedron 2010, 66, 5244. (c) Karlubíková, O.; Palík, M.; Lásiková, A.; Gracza, T. Synthesis 2010, 3449.

8. Ghosh, S.; Pradhan, T. K. J. Org. Chem. 2010, 75, 2107.

9. Brichacek, M.; Batory, L. A.; McGrath, N. A.; Njardarson, J. T. Tetrahedron 2010, 66, 4832.

10. Srinivas, B.; Sridhar, R.; Rama Rao, K. Tetrahedron 2010, 66, 8527. 
11. Zeng, J.; Vedachalam, S.; Xiang, S.; Liu, X.-W. Org. Lett. 2011, 13, 42.

12. (a) Nagarapu, L.; Paparaju, V.; Satyender, A. Bioorg. Med. Chem. Lett. 2008, 18, 2351. (b) Nagarapu, L.; Paparaju, V.; Satyender, A.; Bantu, R. Tetrahedron Lett. 2011, 52, 7075.

13. Vamshikrishna, K.; Srihari, P. Tetrahedron 2012, 68, 1540.

14. Senthilmurugan, A.; Aidhen, I. S. Eur. J. Org. Chem. 2010, 555.

15. (a) Gracza, T.; Jäger, V. Synlett 1992, 191. (b) Gracza, T.; Jäger, V. Synthesis 1994, 1359.

(c) Babjak, M.; Kapitán, P.; Gracza, T. Tetrahedron Lett. 2002, 43, 6983. (d) Babjak, M.; Kapitán, P.; Gracza, T. Tetrahedron 2005, 61, 2471.

16. Mitsunobu, O. Synthesis 1981, 1.

17. Loibnen, H.; Zbiral, E. Helv. Chim. Acta 1981, 59, 2100.

18. (a) Blakemore, P. R.; Cole, W. J.; Kocieński, P. J.; Morley, A. Synlett 1998, 26. (b) Julia, M.; Paris, J.-M. Tetrahedron Lett. 1973, 14, 4833.

19. Box, V. G. S.; Yianikorous, G. P. Heterocycles 1990, 31, 1261.

20. Blakemore, P. R. J. Chem. Soc., Perkin Trans. 1, 2002, 2563.

21. Noskova, V.; Dzubak, P.; Kuzmina, G.; Ludkova, A.; Stehlik, D.; Trojamec, R.; Janostakova, A.; Korinkova, G.; Mihal, V.; Hajduch, M. Neoplasma 2002, 49, 418.

22. Hajduch, M.; Kolar, Z.; Novotny, R.; Hanus, J.; Mihal, V.; Hlobilkova, A.; Noskova, V.; Strnad, M. Anti-Cancer Drugs 1997, 10, 1007. 